\title{
Purinergic P2X7 receptor mediates acetaldehyde-induced hepatic stellate cells activation via PKC-dependent GSK3 $\beta$ pathway
}

Xiaojuan $\mathrm{Wu}^{\mathrm{a}, \mathrm{b}}$, Yuhui Wang ${ }^{\mathrm{a}, \mathrm{b}}$, Sheng Wang ${ }^{\mathrm{a}, \mathrm{b}}$, Rixiang Xu ${ }^{\mathrm{a}, \mathrm{b}}$, Xiongwen $\mathrm{Lv}^{\mathrm{a}, \mathrm{b},{ }^{*}}$

${ }^{a}$ School of Pharmacy, Anhui Medical University, Hefei 230032, China

${ }^{\mathrm{b}}$ Institute for Liver Disease of Anhui Medical University, Anhui Medical University, Hefei 230032, China

\begin{abstract}
The activation of hepatic stellate cells (HSCs) is an essential part in the development of alcoholic liver fibrosis (ALF). In this study, stimulated HSCs with $200 \mu \mathrm{M}$ acetaldehyde for $48 \mathrm{~h}$ was used to imitate alcoholic liver fibrosis in vitro. The western blot and qRT-PCR results showed that P2X7R expression was significantly increased in the activation of HSCs after acetaldehyde treatment. Interestingly, activation of $\mathrm{P} 2 \mathrm{X} 7 \mathrm{R}$ by stimulating with $\mathrm{P} 2 \mathrm{X} 7 \mathrm{R}$ agonist BzATP significantly promoted acetaldehyde-induced CyclinD1 expression, cell proportion in S phase, inflammatory response, and the protein and mRNA levels of $\alpha$-SMA, collagen I. In contrast, blockage of P2X7R by stimulating with the inhibitor A438079 or transfecting with specific siRNA dramatically suppressed acetaldehyde-induced HSCs activation. Furthermore, PKC activation treated with PMA could obviously up-regulate the expression of $\alpha$-SMA and collagen I and the phosphorylation of GSK3 $\beta$, while inhibition of PKC significantly reduced GSK3 $\beta$ activation. Moreover, GSK3 $\beta$ inhibition harvested a dramatic decrease of the mRNA and protein levels of $\alpha$-SMA and collagen I by suppressing GSK3 $\beta$ phosphorylation. Taken together, these results suggested that purinergic P2X7R mediated acetaldehyde-induced activation of HSCs via PKC-dependent GSK3 $\beta$ pathway, which maybe a novel target for limiting HSCs activation.
\end{abstract}

Keywords: P2X7 receptor, hepatic stellate cells, acetaldehyde, PKC, GSK3 $\beta$

\section{Introduction}


Based on the global status report, 9\% of all deaths worldwide (approximately 3.3 million deaths), happened in adults, were associated with alcohol addictive consumption [1]. The major spectrum of alcoholic liver disease (ALD), which is induced by long-term and heavy alcohol drinking, includes steatosis (fatty liver), steatohepatitis (alcoholic hepatitis), fibrosis, cirrhosis, and hepatocellular carcinoma (HCC) $[2,3]$. Steatohepatitis is the early phase of ALD and can be further deteriorated into alcoholic liver fibrosis (ALF) regarding as a breakthrough point in the development of ALD $[4,5]$. Unlike previous views that the extensive liver fibrosis is considered to be irreversible, recent studies suggest that even advanced liver fibrosis is reversible [6], however, the mechanisms remain unknown. Therefore, the research on the molecular pathogenesis pathways and potential therapeutic strategies for ALF has captured growing attention in academic circles.

Despite the pathogenesis of ALF is very intricate involving various molecular and biological mechanisms, a multitude of evidence illustrates that acetaldehyde, serving as the major metabolite of ethanol, plays an essential role in the onset and maintenance of the fibrogenetic process [6]. Hepatic stellate cells (HSCs) is well known to play a key role in the pathogenesis of alcoholic liver fibrosis [7]. Many studies have indicated that acetaldehyde, the principal metabolite of ethanol, promoted type I collagen production [8] and deposition of extracellular matrix (ECM) by activating HSCs, which were the critical cell type involved in the progression of alcoholic liver fibrosis [7, 9]. Furthermore, mounting studies reported that HSCs treated with $200 \mu \mathrm{M}$ acetaldehyde for $48 \mathrm{~h}$ were closely simulated with activation of HSCs in vivo [10-12]. However, the molecular mechanisms, the complicated association between acetaldehyde, HSCs activation and collagen synthesis, remain unclear and need further exploration.

Recently, purinergic receptors, involved in physiology and pathophysiology of the liver, has attracted lots of attention on its important roles in liver fibrotic diseases [13]. P2X7 receptor is an unique member of extracellular ATP-activated purinergic signal family[14] and activating P2X7R contributes to influx of $\mathrm{Ca}^{+}$as well as the release of pro-inflammatory cytokines [15]. Huang and colleagues have demonstrated 
that $\mathrm{A} 438079$, the competitive $\mathrm{P} 2 \mathrm{X} 7 \mathrm{R}$ antagonist, reduced collagen production and the expression of $\alpha$-smooth muscle actin ( $\alpha$-SMA) and TGF- $\beta 1$ in mouse liver fibrosis [16]. Furthermore, Tung $\mathrm{HC}$ et al have also found that the potent P2X7R inhibitor BBG ameliorated liver fibrosis and also significantly decreased hepatic pro-inflammatory cytokines IL-6, IL-1 $\beta$, TNF- $\alpha$ expression in rats with Bile Duct Ligation-induced liver cirrhosis [17]. These results indicate that P2X7 receptor plays a potential role on regulating hepatic fibrosis and targeting P2X7R may be efficacious in the prevention and treatment of hepatic fibrosis. However, the contribution of P2X7R to alcoholic liver fibrosis, involving acetaldehyde-induced HSCs activation, has not been remarkably researched yet.

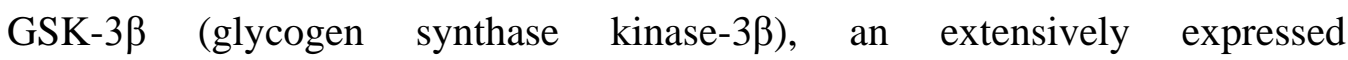
serine/threonine protein kinase, is previously regarded as a mediator of glycogen metabolism [18, 19]. Except its critical role played in glycogen metabolism, recent studies have reported that GSK-3 $\beta$ also plays a very important role in inflammatory response [20] and the regulation of fibrotic disease [21, 22]. GSK-3 $\beta$ inhibition significantly reduced renal fibrosis by suppressing myofibroblast population, collagen I synthesis and inflammatory cytokines [15]. However, Felipe Ortega and groups have found that the P2X7R selective agonist BzATP provoked GSK3 phosphorylation and regulated neuronal survival via the PKC-dependent GSK3 pathway [23]. Therefore, the relationship between $\mathrm{P} 2 \mathrm{X} 7$ receptor and GSK-3 $\beta$ in alcoholic liver fibrosis development progress and acetaldehyde-induced HSCs activation has harvested our group's attention.

In this study, HSCs were cultured and stimulated with $200 \mu \mathrm{M}$ acetaldehyde [10] for $48 \mathrm{~h}$ to establish a vitro model for the study of alcoholic liver fibrosis, which was proposed to simulate the activation process in vivo. Finally, we demonstrated that P2X7 receptor mediates acetaldehyde-induced HSCs activation via PKC-GSK3 $\beta$ signaling pathway.

\section{Materials and Methods}




\section{Antibodies and reagents}

Acetaldehyde (40\%) was provided by Tianjin DaMao Chemical Reagent (Tianjin, China). BzATP (the selective P2X7R agonist) and dimethyl sulfoxide (DMSO) were purchased from Sigma (USA). A438079 (the competitive P2X7R antagonist) and PMA (the PKC agonist) were obtained from Tocris (Ellisville, USA). TDZD-8 (the selective GSK3 $\beta$ antagonist) was supplied by Selleck (USA). SC-3088 (PKC antagonist) and P2X7R antibody were provided by Santa Cruz (California, USA). Antibodies against $\beta$-actin, $\alpha$-smooth muscle actin ( $\alpha$-SMA), collagen type I, PKC, total GSK3 $\beta$ and IL-1 $\beta$, IL-6, IL-18 were obtained from Bioss (Beijing, China). Antibodies against pGSK3 $\beta$, CyclinD1 and TNF- $\alpha$ were purchased from Cell Signaling Technology (USA). Goat anti-rabbit immunoglobulin G (IgG) horse radish peroxidase (HRP) and goat anti-mouse IgG HRP were supplied by ZSGB-BIO (Beijing, China). Trizol reagent was obtained from Invitrogen (California, USA).

\section{Cell culture and cell treatment with acetaldehyde}

The rat HSCs were purchased from KeyGEN Biotechnology (Nanjing, China) and cultured in Dulbecco's modified Eagle's medium (DMEM, KeyGEN, China), which was supplemented with $10 \%$ fetal bovine serum (FBS, Kangyuan, China). All cells were incubated in $5 \% \mathrm{CO} 2$ at $37{ }^{\circ} \mathrm{C}$. HSCs were treated with $200 \mu \mathrm{M}$ acetaldehyde for $48 \mathrm{~h}$ to establish a vitro alcoholic liver fibrosis model.

\section{RNA interference}

Small interfering RNA (siRNA) oligonucleotides against P2X7R gene and negative control sequences were designed and synthesized by the GenePharma (Shanghai, China). The designed sequences were as follows: P2X7R siRNA forward: 5'-CCA GGU AUG AAC AUC UCU UTT-3' and reverse: 5'-AAG AGA UGU UCA UAC CUG GTT-3'; negative control forward: 5'-UUC UCC GAA CGU GUC ACG UTT-3' 
and reverse: 5'-ACG UGA CAC GUU CGG AGA ATT-3'. Cells were transfected with siRNA using Lipofectamin 2000 (Invitrogen, USA) according to the manufacturer's protocol. Western blot analysis were used to identify the efficiency of knockdown.

\section{Quantitative real-time PCR analysis (qRT-PCR)}

Total RNA was extracted from HSCs using Trizol reagent according to the manufacture's protocol. Single-stand cDNA was generated from RNA using a transcripter synthesis kit (Toyobo, Dalian) according to the manufacturer's instructions. Quantitative real-time PCR analyses for the relative level of specific mRNA (P2X7R, collagen I, $\alpha$-SMA, TNF- $\alpha$, IL-1 $\beta$, IL-6, IL-18) were determined by Thermo PIKOREAL real-time PCR detection system using SYBR-Green supermix (Takara). Primer sequences were designed from Sangon Biotech (Shanghai, China) as follows: P2X7R forward: 5'-GTA CAG CTT CCG CCG CCT GG-3' and reverse: 5'-TGC ACA CAG TGG CCA AGC CA-3'; collagen I forward: 5'-GAT CCT GCC GAT GTC GCT AT-3' and reverse: 5'-TGT AGG CTA GCT GTT CTT GCA-3'; $\alpha$-SMA forward: 5'-CGA AGC GCA GAG CAA GAG A-3' and reverse: 5'-CAT GTC GTC CCA GTT GGT GAT-3'; TNF- $\alpha$ forward: 5'-CCA ACA AGG AGG AGA AGT TCC-3' and reverse: 5'-CTC TGC TTG GTG GTT TGC TAC-3'; IL-1 $\beta$ forward: 5'-GGA ACC CGT GTC TTC CTA AAG-3' and reverse: 5'-CTG ACT TGG CAG AGG ACA AAG-3'; IL-6 forward: 5'-TAG TCC TTC CTA CCC CAA CTT CC-3'

and reverse: 5'-TTG GTC CTT AGC CAC TCC TTC-3'; IL-18 forward: 5'-AAA CCC GCC TGT GTT CGA-3' and reverse: 5'-TCA GTC TGG TCT GGG ATT CGT-3'.

\section{Cell cycle analysis}

In order to analyze cell cycle, we performed Cell Cycle Kit (Beyotime, China). HSCs were harvest after cultured $48 \mathrm{~h}$ and washed twice, and then fixed in $70 \%$ cold ethanol 
overnight at $-20^{\circ} \mathrm{C}$. After fixation, cells were washed with cold PBS and collected by centrifugation, and then resuspended with $0.5 \mathrm{~mL}$ propidium iodide (PI) staining buffer, containing $200 \mathrm{mg} / \mathrm{mL}$ RNaseA and $50 \mu \mathrm{g} / \mathrm{mL}$ PI. Then the cell suspensions were incubated at $37{ }^{\circ} \mathrm{C}$ for $30 \mathrm{~min}$ in the dark. Analyses of the cell cycle phase distributions were performed on Laser eight-color flow cytometry (FACSVERSE, USA).

\section{Western blot analysis}

Cells were washed twice and lysed by RIPA buffer (Beyotime, China), containing the protease inhibitor PMSF (Biosharp, USA) for $30 \mathrm{~min}$. After centrifugation at $4{ }^{\circ} \mathrm{C}$ at $12000 \mathrm{rpm}$ for $30 \mathrm{~min}$, protein concentrations were detected by Nucleic acid quantitative instrument (THERMO Nanodrop-2000, USA) and separated by $10 \%$ sodium dodecyl sulfate polyacrylamide gel electrophoresis (SDS-PAGE), and then the extracts were transferred onto polyvinylidene difluoride (PVDF) membranes (Millipore, USA). After blocked in 5\% non-fat milk, the blots were washed and incubated with specific antibodies against P2X7R (1:200), PKC (1:500), $\alpha$-SMA (1:300), collagen I (1:300), CyclinD1 (1:500), $\beta$-actin (1:300), GSK3 $\beta$ (1:300), pGSK3 $\beta$ (1:1000), TNF- $\alpha$ (1:500), IL-1 (1:300), IL-6 (1:300), IL-18 (1:300) overnight at $4{ }^{\circ} \mathrm{C}$. Then the membranes were washed with TBS/Tween 20 there times, and incubated with corresponding secondary antibodies (1:10000) for $1 \mathrm{~h}$ at room temperature. After repeating the washing, protein bands were visualized with enhanced chemiluminescent kit (ECL, Thermo Scientific, USA). Quantitative analyses of immunoblotting images were performed by ImageJ software.

\section{Statistical analysis}

All data were performed at least there times independently and presented as mean \pm SD. One-way ANOVA analysis with SPSS software (version 17.0) was used to estimate the differences between groups. $\mathrm{P}<0.05$ was considered to be statistically 
significant.

\section{Results}

\section{P2X7 receptor are upregulated in acetaldehyde-induced HSCs activation}

To investigate whether the expression of $\mathrm{P} 2 \mathrm{X} 7$ receptor was changed in acetaldehyde-induced HSCs activation, qRT-PCR and western blotting were performed to detect the mRNA and protein levels of $\mathrm{P} 2 \mathrm{X} 7$ receptor. The HSCs treated with $200 \mu \mathrm{M}$ acetaldehyde for $48 \mathrm{~h}$ and then the critical genes related to HSCs activation including $\alpha$-SMA and collagen I were detected. Our results showed that P2X7 receptor and $\alpha$-SMA and collagen I were both significantly up-regulated both in protein (Fig.1A) and mRNA level (Fig.1B) compared with the control group, suggesting that $\mathrm{P} 2 \mathrm{X} 7$ receptor maybe play a important role in the regulation of acetaldehyde-induced HSCs activation.

\section{Effect of P2X7 receptor on acetaldehyde-induced HSCs proliferation}

To explore the effect of $\mathrm{P} 2 \mathrm{X} 7$ receptor on acetaldehyde-induced HSCs proliferation, P2X7R siRNA was used to knock down P2X7 receptor. Transfection efficiency was

detected by Western blot. As shown in Fig.2A, P2X7 receptor was successfully knockdown, and significantly suppressed the protein level of cell cycle regulator CyclinD1, which was correlated with the expression of P2X7 receptor. Moreover, the results of cell cycle analysis showed that silencing of $\mathrm{P} 2 \mathrm{X} 7$ receptor significantly decreased the proportion of cells in the G0/G1 phase and increased in the S phase (Fig.2B) compared with the negative control group, suggesting that knockdown of P2X7 receptor down-regulated HSCs proliferation induced by acetaldehyde.

In addition, HSCs were pretreated with $100 \mu \mathrm{M}$ [24] BzATP, a P2X7R agonist, and $10 \mu \mathrm{M}$ A438079 [25], a P2X7R antagonist, for 1h, and then co-cultured with $200 \mu \mathrm{M}$ acetaldehyde for 48h. As shown in Fig.2C, the expression of CyclinD1 was obviously 
increased in BzATP group and dramatically decreased in A438079 group compared with the acetaldehyde group. Furthermore, the cell cycle analysis showed that BzATP promoted cell population in S phase and A438079 suppressed (Fig.2D). In addition, in A438079 add BzATP group, A438079 could relatively reduce the Cyclin D1 expression and cell proportion in $\mathrm{S}$ phase compared that of BzATP group (Fig.2D), which suggested that inhibition of P2X7R down-regulated acetaldehyde-induced HSCs proliferation.

Taken together, these results revealed that $\mathrm{P} 2 \mathrm{X} 7$ receptor may have great effects on mediating acetaldehyde-induced HSCs proliferation.

\section{Effect of P2X7 receptor on regulating inflammatory response in acetaldehyde-induced HSCs activation}

In order to investigate the association between $\mathrm{P} 2 \mathrm{X} 7$ receptor and the inflammatory response in the process of HSCs activation induced by acetaldehyde, we tested the protein and mRNA expression of TNF- $\alpha$, IL-6, IL-18 and IL-1 $\beta$. After the stimulation of acetaldehyde, TNF- $\alpha$, IL- 6 , IL-18 and IL- $1 \beta$ were directly increased in protein (Fig.3A) and mRNA (Fig.3B) levels compared with the control group, and in contrast, knockdown of P2X7 receptor significantly suppressed their expression compared with the negative control group. Additionally, both mRNA (Fig.3D) and protein (Fig.3C) levels of TNF- $\alpha$, IL-6, IL-18 and IL-1 $\beta$ harvested a dramatic increase in BzATP (the P2X7R agonist) group and an obvious reduction in A439079 (the P2X7 antagonist) group, compared with the acetaldehyde group. And in A438079 add BzATP group, A438079 could relatively decrease the levels of TNF- $\alpha$, IL-6, IL-18 and IL-1 $\beta$ compared with the BzATP group. Taken together, these findings suggested that P2X7 receptor may up-regulate the inflammatory responses, including TNF- $\alpha$, IL-6, IL-18 and IL-1 $\beta$, in acetaldehyde-induced HSCs activation.

The effect of P2X7 receptor on the synthesis of $\alpha$-SMA and collagen I in acetaldehyde-induced HSCs activation 
To identify the function role of $\mathrm{P} 2 \mathrm{X} 7$ receptor in HSCs activation induced by acetaldehyde, we detected the expression of $\alpha$-SMA and collagen I by western blot and qRT-PCR. Silencing of P2X7 receptor significantly suppressed the protein (Fig.4A) and mRNA (Fig.4B) expression of collagen I and $\alpha$-SMA induced by acetaldehyde compared with the negative control group. Moreover, $\alpha$-SMA and collagen I were significantly enhanced in BzATP (the P2X7R agonist) group and decreased in A438079 (the P2X7R antagonist) group in protein (Fig.4C) and mRNA (Fig.4D) levels compared with the acetaldehyde group. In addition, in A438079 add BzATP group, A438079 relatively reversed the levels of $\alpha$-SMA and collagen I compared that of BzATP group. These data suggested that $\mathrm{P} 2 \mathrm{X} 7$ receptor up-regulated the expression of collagen I and $\alpha$-SMA in the activation of HSCs induced by acetaldehyde.

\section{The effect of P2X7 receptor on PKC-GSK3ß pathway in acetaldehyde-induced HSCs activation}

To further dissect whether $\mathrm{P} 2 \mathrm{X} 7$ receptor mediates HSCs activation through PKC-GSK3 $\beta$ pathway, we detected the protein levels of PKC, pGSK3 $\beta$ and GSK3 3 . As shown in Fig.5A and Fig.5B, after stimulated with acetaldehyde, the protein level of PKC (Fig.5A) and the ratio of pGSK3 $\beta / G S K 3 \beta$ (Fig.5B) were significantly increased compared with the control group, and reversely, knockdown of P2X7 receptor apparently suppressed their expression compared with the negative control group. Furthermore, compared with the acetaldehyde group, BzATP (the P2X7R agonist) significantly increased the protein level of PKC (Fig.5C) and the ratio of pGSK3ß/GSK3 $\beta$ (Fig.5D), and A438079 (the P2X7R antagonist) led to a dramatic decrease. And in A438079 add BzATP group, A438079 could relatively reduce PKC expression and GSK3 $\beta$ phosphorylation compared with BzATP group. Taken together, these findings indicated that $\mathrm{P} 2 \mathrm{X} 7$ receptor may enhance the expression of PKC and promote phosphorylation of GSK3 3 to mediate acetaldehyde-induced HSCs 
activation.

\section{The effect of PKC on PKC-GSK3 $\beta$ pathway in acetaldehyde-induced HSCs activation}

To further confirm the role of PKC in acetaldehyde-induced HSCs activation, here we examined the influence of the PKC agonist PMA and inhibitor SC-3088 on PKC-GSK3 $\beta$ signaling. HSCs were pretreated with 100nM PMA and 10mg/L SC-3088 for $1 \mathrm{~h}$, and then co-cultured with $200 \mu \mathrm{M}$ acetaldehyde for $48 \mathrm{~h}$. The result showed that PKC was successfully activated and inhibited (Fig.6A). Then, PMA triggered a significant increase of pGSK3 $\beta /$ GSK3 $\beta$ proportion and SC-3088 reversely caused an apparent reduction compared with the acetaldehyde group (Fig.6B). Furthermore, $\alpha$-SMA and collagen I harvested the same alteration as the rate of pGSK3 $\beta /$ GSK3 $\beta$ in mRNA (Fig.6D) and protein levels (Fig.6C). These results clearly illustrated that PKC up-regulated acetaldehyde-induced HSCs activation by stimulating the phosphorylation of GSK3 $\beta$.

\section{Inhibition of GSK3ß down-regulates HSCs activation induced by acetaldehyde}

To further explore the influence of GSK3 $\beta$ on acetaldehyde-induced HSCs activation, the selective GSK3 $\beta$ inhibitor TDZD-8 was used. Firstly, HSCs were treated with $10 \mu \mathrm{M}$ TDZD-8 for $1 \mathrm{~h}$, and then co-cultured with $200 \mu \mathrm{M}$ acetaldehyde for $48 \mathrm{~h}$. The results in Fig.7A showed that acetaldehyde up-regulated GSK3 $\beta$ phosphorylation and TDZD-8 successfully inhibited the phosphorylation of GSK3 $\beta$. Moreover, the protein (Fig.7B) and mRNA (Fig.7C) levels of $\alpha$-SMA and collagen I were significantly decreased in TDZD-8 group compared with the acetaldehyde group. Taken together, these results distinctly suggested that inhibition of GSK3 $\beta$ down-regulated HSCs activation induced by acetaldehyde, and further confirmed that $\mathrm{P} 2 \mathrm{X} 7$ receptor mediated acetaldehyde-induced activation of HSCs via PKC-GSK3 $\beta$ pathway. 


\section{Discussion}

ALD is a global health problem and ALF is a turning point in ALD progression [26]. In the development of hepatic fibrosis, HSCs are quiescent for storing Vitamin A in normal liver [27], and activated to transform into proliferative myofibroblast cells as the main source of excess ECM production in the injured liver [28]. Therefore, activated HSCs are regarded as a major target or the reversal or attenuation of hepatic fibrosis [29]. Metabolic derivatives of alcohol, acetaldehyde, has been reported to stimulate collagen I synthesis [30] and $\alpha$-SMA production in HSCs [31]. Moreover, growing evidence showed that activating HSCs with $200 \mu \mathrm{M}$ acetaldehyde for $48 \mathrm{~h}$ could similarly simulate activation of HSCs in vivo for the model of alcoholic liver fibrosis [10-12].

The $\mathrm{P} 2 \mathrm{X} 7$ receptor, which is widely distributed in liver, being present in various cellular subtypes such as hepatocytes, kupffer cells and endothelial cells [32], has emerged as a relevant target among purinergic family. In our present study, western blot and qRT-PCR were used to quantify P2X7R, collagen I and $\alpha$-SMA in mRNA and protein levels in HSCs. We found that P2X7R was significantly increased accompanying with the increase of collagen I and $\alpha$-SMA in HSCs activation induced by acetaldehyde, which confirmed that P2X7R was also present in rat HSCs and its activation may be largely responsible for HSCs activation induced by acetaldehyde. Recently, experiments have shown that $\mathrm{P} 2 \mathrm{X} 7$ receptor up-regulated the proliferation of Schwann cell in injured nerves [33] and in contrast different cell types P2X7R blockade or stimulation in different cell types showed different or same influence on cell proliferation in mesothelioma [34]. However, the effect of P2X7R on HSCs had no available information yet. In our previous research, our results showed that in response to treatment with acetaldehyde, HSCs were activated compared with the control group, and the proliferation was suppressed by incubation with the selective P2X7R antagonist A438079, as well as increased by stimulation in the presence of the competitive P2X7R agonist BzATP compared with the model group. Moreover, knockdown of P2X7R resulted in the suppression of HSCs proliferation. These results 
suggested that P2X7R up-regulated the proliferation of $\mathrm{HSCs}$ induced by acetaldehyde.

According to the recent studies, P2X7R activation can affect various proinflammatory cytokines levels involving IL1 $\beta$ and IL-18 $[35,36]$. In addition, HSCs are not only the main producer of ECM, but also the target of proinflammatory regulators.[37, 38]. In our present work, western blot and qRT-PCR were used to determine the expression of TNF- $\alpha$, IL- 6 , IL-18 and IL-1 $\beta$ in the process of acetaldehyde-induced HSCs activation. Our results showed that acetaldehyde may have a positive effect on inflammatory response in HSCs, involving not only IL-18 and IL- $1 \beta$ but also TNF- $\alpha$ and IL-6 compared with that of control group. Further results indicated that P2X7R participated in the up-regulation of TNF- $\alpha$, IL-6, IL-18 and IL-1 $\beta$ levels in HSCs activation induced by acetaldehyde.

Up to now, it is reported that mouse liver fibrosis can be attenuated by block of $\mathrm{P} 2 \mathrm{X} 7 \mathrm{R}$ [16] and P2X7R stimulation can increase the danger in pulmonary fibrosis [39]. Our previous results have showed that knockdown or block of P2X7R contributed to the dramatic suppression of collagen I and $\alpha$-SMA in mRNA and protein levels. In addition, P2X7R activation triggered an obvious over-expression. These results further indicated that P2X7R participated in regulation of HSCs activation induced by acetaldehyde. However, the potential pathway remained no available information yet in HSCs.

Notably, P2X7R stimulation is highly permeable to calcium influx[40], which could induce $\mathrm{Ca}^{2+}$-dependent-PKC activation [41, 42] and pGSK3 $\beta$ expression [23]. To gain insight into pathway mediated by $\mathrm{P} 2 \mathrm{X} 7 \mathrm{R}$, the protein levels of PKC, pGSK3 $\beta$ and GSK3 $\beta$ were determined. Data from our previous study showed that stimulating acetaldehyde-induced HSCs with BzATP resulted in a significant increase of PKC and pGSK3 $\beta / G S K 3 \beta$ level, as well as the treatment using A438079 led to a remarkable decrease. In addition, silencing of P2X7R provided a negative effect on PKC and GSK3 $\beta$ phosphorylation. These results provided a novel insight into mechanisms that P2X7R may regulate acetaldehyde-induced HSCs activation through PKC/GSK3 $\beta$ pathway. 
To further elucidate the PKC-GSK3 $\beta$ pathway, the PKC agonist PMA and antagonist SC-3088 were used to identify the potential role of PKC, and we found that PMA dramatically stimulated expression of PKC, pGSK3 $\beta / G S K 3 \beta$, collagen I and a-SMA, as well as SC-3088 obviously suppressed. These data confirmed that PKC stimulated HSCs activation induced by acetaldehyde.

Paradoxically, previous studies have revealed the dramatic expression of pGSK3 $\beta$ protein induced by acetaldehyde in human HSCs but the GSK3 $\beta$ protein kept unchanged [43]. In our prior study, pGSK3 $\beta$ protein was increased but GSK3 $\beta$ protein was suppressed. Moreover, compared with the model control, both of BzATP and PMA reduced the expression of GSK3 $\beta$ protein and contrastly facilitated pGSK3 $\beta$ level, as well as treatment with A438079 and SC-3088 and TDZD-8 harvested the promotion of GSK3 $\beta$ and the suppression of pGSK3 $\beta$. Furthermore, compared with negative control, knockdown of P2X7R stimulated the expression of GSK3 $\beta$ while reduced the level of pGSK3 $\beta$. But the reason why GSK3 $\beta$ contributed to the same functional influence with differential expression in the activation of HSCs induced by acetaldehyde is not clearly estimated and need further study. In the other words, the ratio of pGSK3 $\beta /$ GSK3 $\beta$ elucidated acetaldehyde can promote the phosphorylation of GSK3 $\beta$ to up-regulate the levels of -SMA and collagen I. Furthermore, inhibition of GSK3 $\beta$ reduced acetaldehyde-induced expression of $\alpha$-SMA and collagen I by suppressing the phosphorylation of GSK3 $\beta$ as compared that of the model group, which illustrated the close association between P2X7R, PKC and GSK3 $\beta$ in acetaldehyde-induced HSCs activation.

\section{Conclusion}

In this study, we demonstrated that P2X7R was existed in rat HSCs and probably exerted positive influence via PKC-dependent GSK3 $\beta$ pathway. At present, we concluded that acetaldehyde may up-regulated the HSCs proliferation, inflammatory response, the synthesis of $\alpha$-SMA and collagen I and PKC and the phosphorylation of GSK3 $\beta$, which could be activated by P2X7R agonist and suppressed by P2X7R 
inhibitor. Moreover, PKC activation had positive effects on the expression of $\alpha$-SMA and collagen I and GSK3 $\beta$ phosphorylation, and PKC inhibitor had the opposite effects. Furthermore, GSK3 $\beta$ inhibition suppressed the levels of $\alpha$-SMA and collagen I by reducing GSK3 $\beta$ phosphorylation. This study not only provides a bran-new insight into the character of $\mathrm{P} 2 \mathrm{X} 7 \mathrm{R}$ in the progression of alcoholic-induced liver fibrosis but also reveals PKC-dependent GSK3 $\beta$ signaling pathway with possible target of P2X7R inhibitor-based therapy.

\section{Acknowledgments}

This project was supported by the National Science Foundation of China (No. 81270498), 2016 Annual Leading Talent Introduction and Cultivation Project in Universities (No.gxbjZD2016032).

\section{References}

[1] L.R. Gowing, R.L. Ali, S. Allsop, J. Marsden, E.E. Turf, R. West, J. Witton, Global statistics on addictive behaviours: 2014 status report, Addiction. 110 (2015) 904-19.

[2] B. Gao, R. Bataller, Alcoholic liver disease: pathogenesis and new therapeutic targets, Gastroenterology. 141 (2011) 1572-85.

[3] S. Bala, G. Szabo, MicroRNA Signature in Alcoholic Liver Disease, International journal of hepatology. 2012 (2012) 498232.

[4] E.S. Orman, G. Odena, R. Bataller, Alcoholic liver disease: pathogenesis, management, and novel targets for therapy, Journal of gastroenterology and hepatology. 28 Suppl 1 (2013) 77-84.

[5] A.T. Duddempudi, Immunology in alcoholic liver disease, Clinics in liver disease. 16 (2012) 687-98.

[6] S.V. Siegmund, S. Dooley, D.A. Brenner, Molecular mechanisms of alcohol-induced hepatic fibrosis, Digestive diseases. 23(2005) 264-74.

[7] V. Hernandez-Gea, S.L. Friedman, Pathogenesis of liver fibrosis, Annual review of pathology. 6 (2011) 425-56.

[8] K. Reyes-Gordillo, R. Shah, J. Arellanes-Robledo, Z. Hernandez-Nazara, A.R. Rincon-Sanchez, Y. Inagaki, M. Rojkind, M.R. Lakshman, Mechanisms of action of acetaldehyde in the up-regulation of the human alpha2(I) collagen gene in hepatic stellate cells: key roles of Ski, SMAD3, SMAD4, and SMAD7, The American journal of pathology. 184 (2014) 1458-67.

[9] T. Mello, E. Ceni, C. Surrenti, A. Galli, Alcohol induced hepatic fibrosis: role of acetaldehyde, Molecular aspects of medicine. 29 (2008) 17-21.

[10] H. Wang, W. Guan, W. Yang, Q. Wang, H. Zhao, F. Yang, X. Lv, J. Li, Caffeine inhibits the activation of hepatic stellate cells induced by acetaldehyde via adenosine A2A receptor mediated by the CAMP/PKA/SRC/ERK1/2/P38 MAPK signal pathway, PloS one. 9 (2014) e92482. 
[11] Y. Yang, H. Wang, X. Lv, Q. Wang, H. Zhao, F. Yang, Y. Yang, J. Li, Involvement of cAMP-PKA pathway in adenosine $\mathrm{A} 1$ and $\mathrm{A} 2 \mathrm{~A}$ receptor-mediated regulation of acetaldehyde-induced activation of HSCS, Biochimie. 115 (2015) 59-70.

[12] Y. Yang, F. Yang, X. Wu, X. Lv, J. Li, EPAC activation inhibits acetaldehyde-induced activation and proliferation of hepatic stellate cell via Rap1, Canadian journal of physiology and pharmacology. 94 (2016) 498-507.

[13] G. Burnstock, B. Vaughn, S.C. Robson, Purinergic signalling in the liver in health and disease, Purinergic signalling. 10 (2014) 51-70.

[14] M. Jindrichova, H. Zemkova, Purinergic P2X family and specific features of the P2X7 subtype, Ceskoslovenska fysiologie / Ustredni ustav biologicky. 62 (2013) 40-6.

[15] C. Volonte, S. Apolloni, S.D. Skaper, G. Burnstock, P2X7 receptors: channels, pores and more, CNS \& neurological disorders drug targets. 11 (2012) 705-21.

[16] C. Huang, W. Yu, H. Cui, Y. Wang, L. Zhang, F. Han, T. Huang, P2X7 blockade attenuates mouse liver fibrosis, Molecular medicine reports. 9 (2014) 57-62.

[17] H.C. Tung, F.Y. Lee, S.S. Wang, M.H. Tsai, J.Y. Lee, T.I. Huo, H.C. Huang, C.L. Chuang, H.C. Lin, S.D. Lee, The Beneficial Effects of P2X7 Antagonism in Rats with Bile Duct Ligation-induced Cirrhosis, PloS one. 10 (2015) e0124654.

[18] P. Cohen, M. Goedert, GSK3 inhibitors: development and therapeutic potential, Nature reviews. Drug discovery. 3 (2004) 479-87.

[19] G.V. Rayasam, V.K. Tulasi, R. Sodhi, J.A. Davis, A. Ray, Glycogen synthase kinase 3: more than a namesake, British journal of pharmacology. 156 (2009) 885-98.

[20] H. Zhang, W. Wang, H. Fang, Y. Yang, X. Li, J. He, X. Jiang, W. Wang, S. Liu, J. Hu, A. Liu, U. Dahmen, O. Dirsch, GSK-3beta inhibition attenuates CLP-induced liver injury by reducing inflammation and hepatic cell apoptosis, Mediators of inflammation. 2014 (2014) 629507.

[21] H.A. Baarsma, L.H. Engelbertink, L.J. van Hees, M.H. Menzen, H. Meurs, W. Timens, D.S. Postma, H.A. Kerstjens, R. Gosens, Glycogen synthase kinase-3 (GSK-3) regulates TGF-beta(1)-induced differentiation of pulmonary fibroblasts, British journal of pharmacology. 169 (2013) 590-603.

[22] S.P. Singh, S. Tao, T.A. Fields, S. Webb, R.C. Harris, R. Rao, Glycogen synthase kinase-3 inhibition attenuates fibroblast activation and development of fibrosis following renal ischemia-reperfusion in mice, Disease models \& mechanisms. 8 (2015) 931-40.

[23] F. Ortega, R. Perez-Sen, V. Morente, E.G. Delicado, M.T. Miras-Portugal, P2X7, NMDA and BDNF receptors converge on GSK3 phosphorylation and cooperate to promote survival in cerebellar granule neurons, Cellular and molecular life sciences : CMLS. 67 (2010) 1723-33.

[24] F. Ortega, R. Perez-Sen, E.G. Delicado, M.T. Miras-Portugal, P2X7 nucleotide receptor is coupled to GSK-3 inhibition and neuroprotection in cerebellar granule neurons, Neurotoxicity research. 15 (2009) 193-204.

[25] H.K. Tsao, P.H. Chiu, S.H. Sun, PKC-dependent ERK phosphorylation is essential for P2X7 receptor-mediated neuronal differentiation of neural progenitor cells, Cell death \& disease. 4 (2013) e751.

[26] P. Kocabayoglu, S.L. Friedman, Cellular basis of hepatic fibrosis and its role in inflammation and cancer, Frontiers in bioscience. 5 (2013) 217-30.

[27] A.Y. Hui, S.L. Friedman, Molecular basis of hepatic fibrosis, Expert reviews in molecular medicine. 5 (2003) 1-23.

[28] R. Omar, J. Yang, H. Liu, N.M. Davies, Y. Gong, Hepatic Stellate Cells in Liver Fibrosis and 
siRNA-Based Therapy, Reviews of physiology, biochemistry and pharmacology. (2016).

[29] M. Ghazwani, Y. Zhang, X. Gao, J. Fan, J. Li, S. Li, Anti-fibrotic effect of thymoquinone on hepatic stellate cells, Phytomedicine : international journal of phytotherapy and phytopharmacology. 21 (2014) 254-60.

[30] G. Svegliati-Baroni, F. Ridolfi, A. Di Sario, S. Saccomanno, E. Bendia, A. Benedetti, P. Greenwel, Intracellular signaling pathways involved in acetaldehyde-induced collagen and fibronectin gene expression in human hepatic stellate cells, Hepatology. 33 (2001) 1130-40.

[31] Y. Liu, J. Brymora, H. Zhang, B. Smith, M. Ramezani-Moghadam, J. George, J. Wang, Leptin and acetaldehyde synergistically promotes alphaSMA expression in hepatic stellate cells by an interleukin 6-dependent mechanism, Alcoholism, clinical and experimental research. 35 (2011) 921-8.

[32] M. Fausther, E. Gonzales, J.A. Dranoff, Role of purinergic P2X receptors in the control of liver homeostasis, Wiley interdisciplinary reviews. Membrane transport and signaling. 1 (2012) 341-348.

[33] X.M. Song, X.H. Xu, J. Zhu, Z. Guo, J. Li, C. He, G. Burnstock, H. Yuan, Z. Xiang, Up-regulation of P2X7 receptors mediating proliferation of Schwann cells after sciatic nerve injury, Purinergic signalling. 11 (2015) 203-13.

[34] F. Amoroso, E. Salaro, S. Falzoni, P. Chiozzi, A.L. Giuliani, G. Cavallesco, P. Maniscalco, A. Puozzo, I. Bononi, F. Martini, M. Tognon, F. Di Virgilio, P2X7 targeting inhibits growth of human mesothelioma, Oncotarget. (2016).

[35] R. Hoque, M.A. Sohail, S. Salhanick, A.F. Malik, A. Ghani, S.C. Robson, W.Z. Mehal, P2X7 receptor-mediated purinergic signaling promotes liver injury in acetaminophen hepatotoxicity in mice, American journal of physiology. Gastrointestinal and liver physiology. 302 (2012) G1171-9.

[36] S. Deplano, H.T. Cook, R. Russell, L. Franchi, S. Schneiter, G. Bhangal, R.J. Unwin, C.D. Pusey, F.W. Tam, J. Behmoaras, P2X7 receptor-mediated NIrp3-inflammasome activation is a genetic determinant of macrophage-dependent crescentic glomerulonephritis, Journal of leukocyte biology. 93 (2013) 127-34.

[37] R. Bataller, D.A. Brenner, Hepatic stellate cells as a target for the treatment of liver fibrosis, Seminars in liver disease. 21 (2001) 437-51.

[38] S.L. Friedman, Molecular regulation of hepatic fibrosis, an integrated cellular response to tissue injury, The Journal of biological chemistry. 275 (2000) 2247-50.

[39] N. Riteau, P. Gasse, L. Fauconnier, A. Gombault, M. Couegnat, L. Fick, J. Kanellopoulos, V.F. Quesniaux, S. Marchand-Adam, B. Crestani, B. Ryffel, I. Couillin, Extracellular ATP is a danger signal activating $\mathrm{P} 2 \mathrm{X7}$ receptor in lung inflammation and fibrosis, American journal of respiratory and critical care medicine. 182 (2010) 774-83.

[40] R.A. North, Molecular physiology of P2X receptors, Physiological reviews. 82 (2002) 1013-67.

[41] C.M. Wang, Y.Y. Chang, S.H. Sun, Activation of P2X7 purinoceptor-stimulated TGF-beta 1 mRNA expression involves PKC/MAPK signalling pathway in a rat brain-derived type-2 astrocyte cell line, RBA-2, Cellular signalling. 15 (2003) 1129-37.

[42] A.C. Hung, S.H. Sun, The P2X(7) receptor-mediated phospholipase D activation is regulated by both PKC-dependent and PKC-independent pathways in a rat brain-derived Type-2 astrocyte cell line, RBA-2, Cellular signalling. 14 (2002) 83-92.

[43] J. Arellanes-Robledo, K. Reyes-Gordillo, R. Shah, J.A. Dominguez-Rosales, Z.H. Hernandez-Nazara, F. Ramirez, M. Rojkind, M.R. Lakshman, Fibrogenic actions of acetaldehyde are beta-catenin dependent but Wingless independent: a critical role of nucleoredoxin and reactive oxygen species in human hepatic stellate cells, Free radical biology \& medicine. 65 (2013) 1487-96. 


\section{Figure legend}

Fig.1 The protein expression (A) and mRNA level (B) of P2X7 receptor, $\alpha$-SMA and collagen I in control group and acetaldehyde group. The data were representative of at least three independent experiments. All values were expressed as mean \pm SEM. ${ }^{* *} \mathrm{P}<0.01$ vs. the control group.

Fig.2 P2X7 receptor up-regulated the proliferation of HSCs activation induced by acetaldehyde. (A) P2X7R was successfully knockdown and reduced the expression of CyclinD1. The data were representative of at least three independent experiments. All values were expressed as mean \pm SEM. ${ }^{* *} \mathrm{P}<0.01$ vs. the control group, ${ }^{\#} \mathrm{P}<0.05$, ${ }^{\# \#} \mathrm{P}<0.01$ vs. the negative control group. (B) Cell cycle analysis for knockdown of P2X7R. The data were representative of at least three independent experiments. All values were expressed as mean $\pm \mathrm{SEM}$. ${ }^{*} \mathrm{P}<0.05$ vs. the control group, ${ }^{\#} \mathrm{P}<0.05$ vs. the negative control group. (C) The effect of P2X7R agonist BzATP $(100 \mu \mathrm{M})$ and P2X7R antagonist A438079 $(10 \mu \mathrm{M})$ on the expression of CyclinD1. The data were representative of at least three independent experiments. All values were expressed as mean \pm SEM. ${ }^{* *} \mathrm{P}<0.01$ vs. the control group, ${ }^{\#} \mathrm{P}<0.05,{ }^{\# \#} \mathrm{P}<0.01$ vs. the acetaldehyde group, ${ }^{\&} \mathrm{P}<0.05$ vs. the BzATP group. (D) The effect of P2X7R agonist BzATP (100 
$\mu \mathrm{M})$ and P2X7R antagonist A438079 $(10 \mu \mathrm{M})$ on the cell cycle analysis. The data were representative of at least three independent experiments. All values were expressed as mean \pm SEM. ${ }^{*} \mathrm{P}<0.05$ vs. control group, ${ }^{\#} \mathrm{P}<0.05$ vs. the model group, ${ }^{\&} \mathrm{P}<0.05$ vs. the BzATP group.

Fig.3 P2X7 receptor up-regulated the expression of TNF- $\alpha$, IL-6, IL-18 and IL-1 $\beta$ in acetaldehyde-induced HSCs. Knockdown of P2X7R suppressed the protein expression (A) and mRNA level (B) of TNF- $\alpha$, IL-6, IL-18 and IL-1 $\beta$. The data were representative of at least three independent experiments. All values were expressed as mean \pm SEM. ${ }^{* *} \mathrm{P}<0.01,{ }^{* * *} \mathrm{P}<0.001$ vs. the control group, ${ }^{\# \#} \mathrm{P}<0.01,{ }^{\# \# \#} \mathrm{P}<0.001$ vs. the negative control group. The effect of P2X7R agonist BzATP $(100 \mu \mathrm{M})$ and P2X7R antagonist A438079 $(10 \mu \mathrm{M})$ on the protein expression (C) and mRNA level (D) of TNF- $\alpha$, IL-6, IL-18 and IL-1 $\beta$. The data were representative of at least three independent experiments. All values were expressed as mean \pm SEM. ${ }^{* *} \mathrm{P}<0.01$ vs. the control group, ${ }^{\#} \mathrm{P}<0.05,{ }^{\# \#} \mathrm{P}<0.01$ vs. the acetaldehyde group, ${ }^{\&} \mathrm{P}<0.05,{ }^{\& \&} \mathrm{P}<0.01$ vs. the BzATP group.

Fig.4 P2X7 receptor up-regulated the expression of $\alpha$-SMA and collagen $I$ in acetaldehyde-induced HSCs activation. Knockdown of P2X7R decreased the protein (A) and mRNA (B) level of $\alpha$-SMA and collagen I. The data were representative of at least three independent experiments. All values were expressed as mean \pm SEM. ${ }^{* *} \mathrm{P}<0.01$ vs. control group, ${ }^{\# \#} \mathrm{P}<0.01$ vs. the negative control group. The protein expression (C) and mRNA level (D) of $\alpha$-SMA and collagen I were increased and decreased by P2X7R agonist BzATP $(100 \mu \mathrm{M})$ and P2X7R antagonist A438079 $(10 \mu \mathrm{M})$. The data were representative of at least three independent experiments. All values were expressed as mean \pm SEM. ${ }^{* *} \mathrm{P}<0.01$ vs. the control group, ${ }^{\#} \mathrm{P}<0.05$, ${ }^{\# \#} \mathrm{P}<0.01$ vs. the acetaldehyde group, ${ }^{\& \&} \mathrm{P}<0.01$ vs. the BzATP group.

Fig.5 P2X7 receptor promoted PKC expression and GSK3 $\beta$ phosphorylation in HSCs activation induced by acetaldehyde. The expression of PKC (A) and the phosphorylation of GSK3 $\beta$ (B) were down-regulated by silencing of P2X7R. The data were representative of at least three independent experiments. All values were expressed as mean \pm SEM. ${ }^{* *} \mathrm{P}<0.01$ vs. the control group, ${ }^{\# \#} \mathrm{P}<0.01$ vs. the negative 
control group. The PKC level (C) and GSK3 $\beta$ phosphorylation (D) were influenced by P2X7R agonist BzATP $(100 \mu \mathrm{M})$ and P2X7R antagonist A438079 $(10 \mu \mathrm{M})$. The data were representative of at least three independent experiments. All values were expressed as mean \pm SEM. ${ }^{*} \mathrm{P}<0.05,{ }^{* *} \mathrm{P}<0.01$ vs. the control group, ${ }^{\#} \mathrm{P}<0.05,{ }^{\# \#} \mathrm{P}<0.01$ vs. the acetaldehyde group, ${ }^{\&} \mathrm{P}<0.05,{ }^{\& \&} \mathrm{P}<0.01$ vs. the BzATP group.

Fig.6 The effect of PKC agonist PMA (100nM) and PKC inhibitor SC-3088 (10mg/L on the PKC expression (A), GSK3 $\beta$ phosphorylation (B) and the protein expression (C) and mRNA level (D) of $\alpha$-SMA and collagen I in the activation of HSCs induced by acetaldehyde. The data were representative of at least three independent experiments. All values were expressed as mean \pm SEM. ${ }^{* *} \mathrm{P}<0.01$ vs. the control group, ${ }^{\#} \mathrm{P}<0.05,{ }^{\#} \mathrm{P}<0.01$ vs. the acetaldehyde group.

Fig.7 The impact of GSK3 $\beta$ inhibitor TDZD-8 $(10 \mu \mathrm{M})$ on the GSK3 $\beta$ phosphorylation (A), the protein expression (B) and mRNA level (C) of $\alpha$-SMA and collagen I in acetaldehyde-induced HSCs activation. The data were representative of at least three independent experiments. All values were expressed as mean \pm SEM. ${ }^{* *} \mathrm{P}<0.01,{ }^{* * *} \mathrm{P}<0.01$ vs. the control group, ${ }^{\#} \mathrm{P}<0.05,{ }^{\# \#} \mathrm{P}<0.01,{ }^{\# \# \#} \mathrm{P}<0.01$ vs. the acetaldehyde group. 
A. acetaldehyde - +

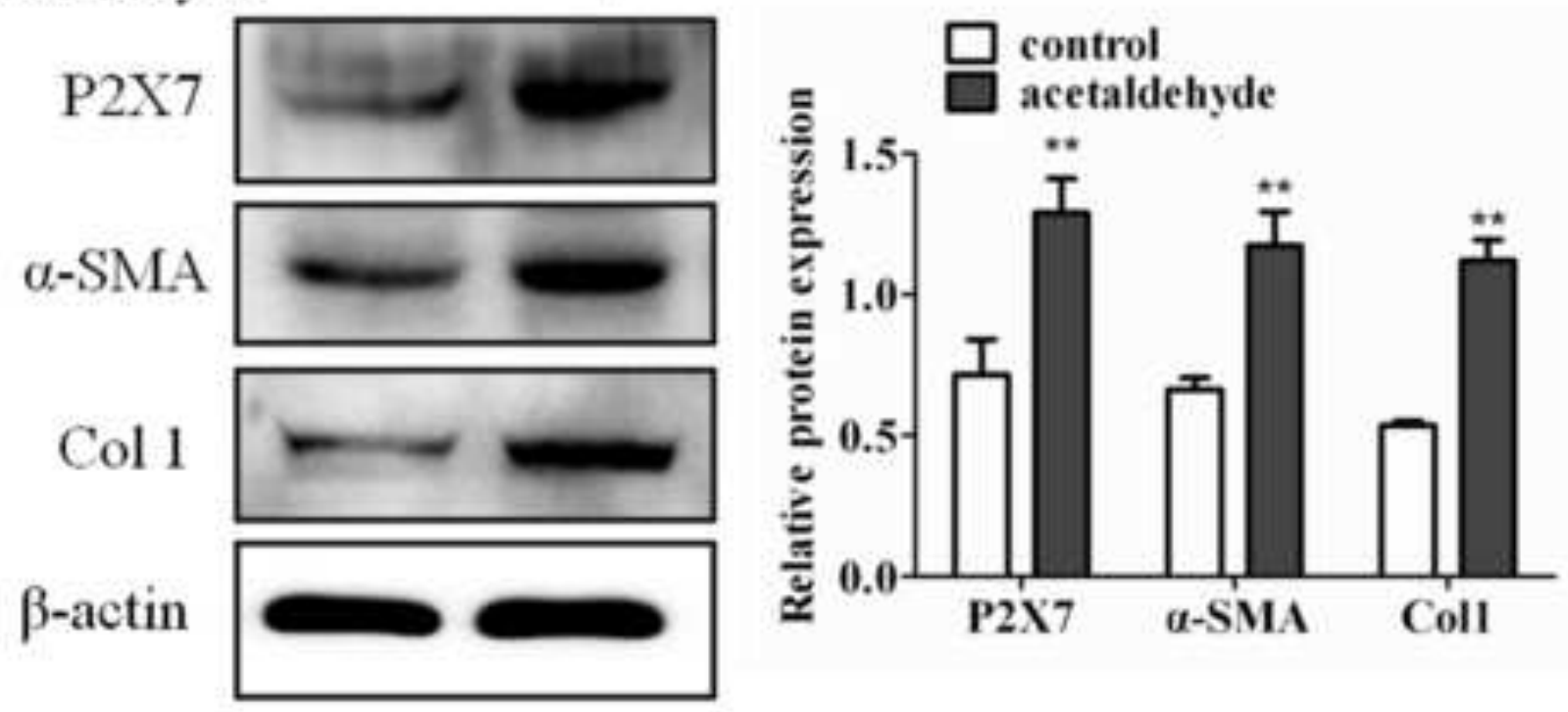

B.

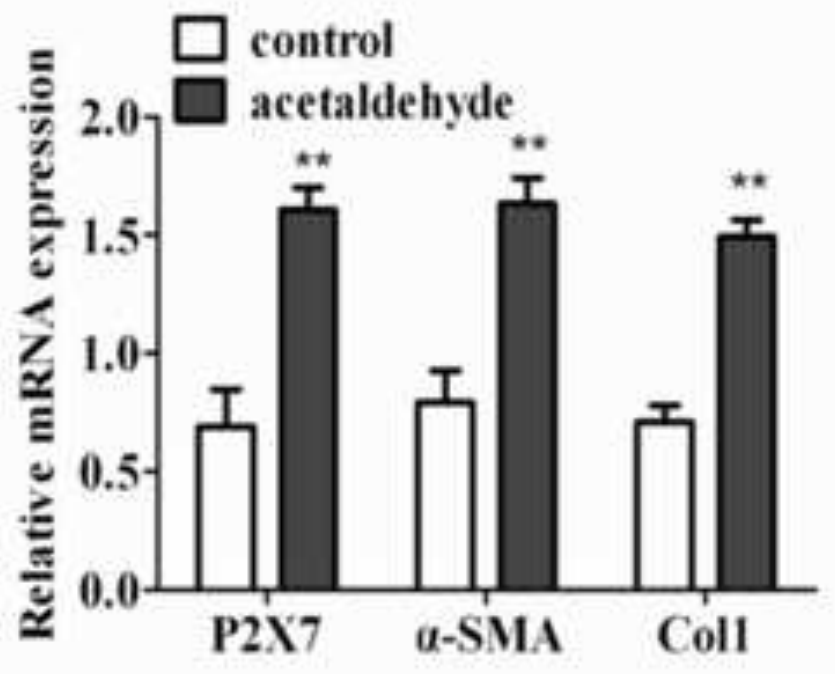


A. acetaldeliyde - +++

Negative control - - +

P2X7 SiRNA - - + +

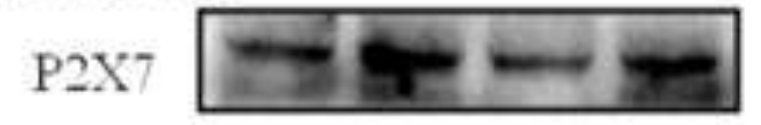

CyclinD1
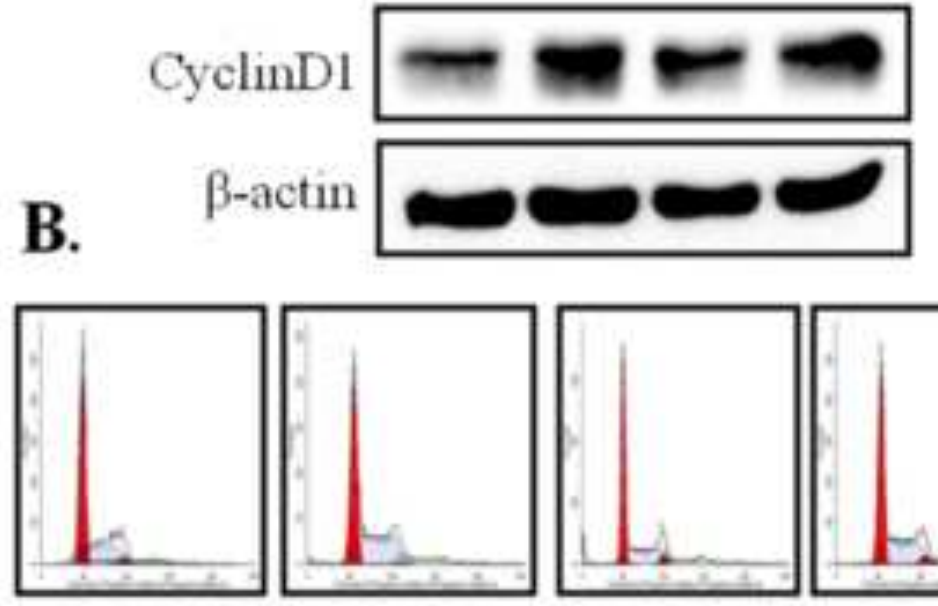

control acetaldehyde siRNA Negative
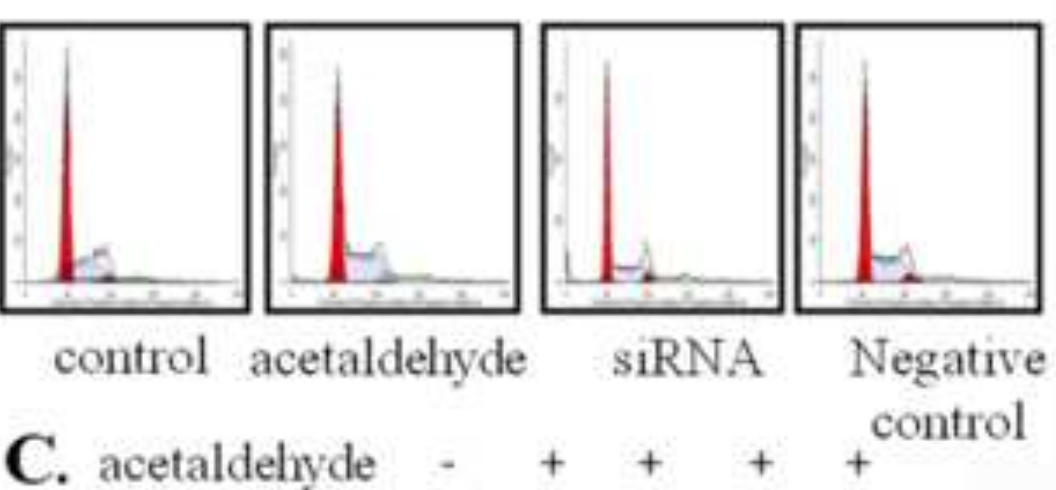
$100 \mu \mathrm{MBzATP}$ - - + + + $10 \mu \mathrm{MA438079} \mathrm{-} \mathrm{+} \mathrm{+} \mathrm{+}$
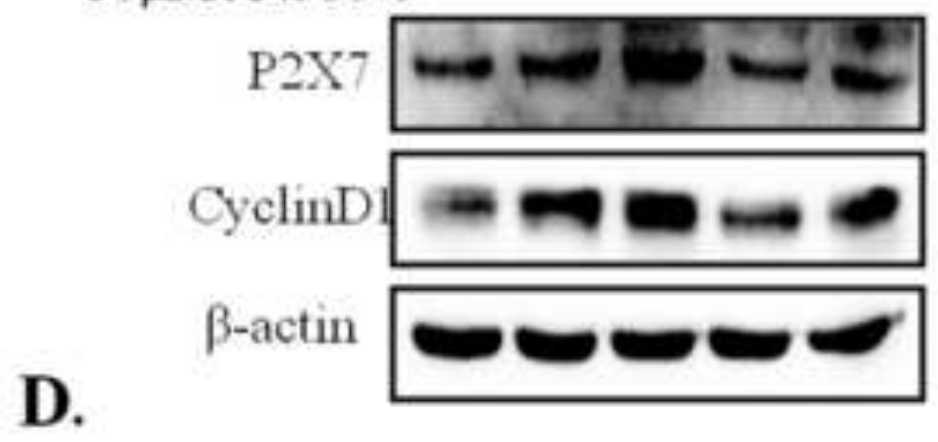

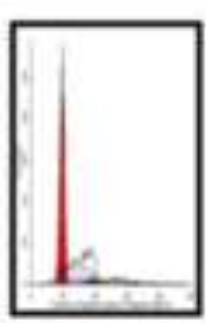

control acetaldehyde BzATP

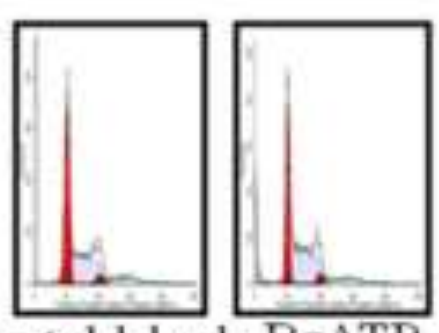

A438079

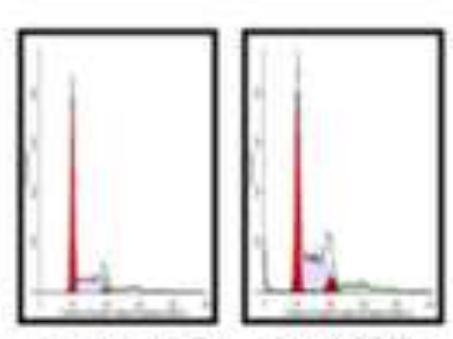

BzATP+ A 438079
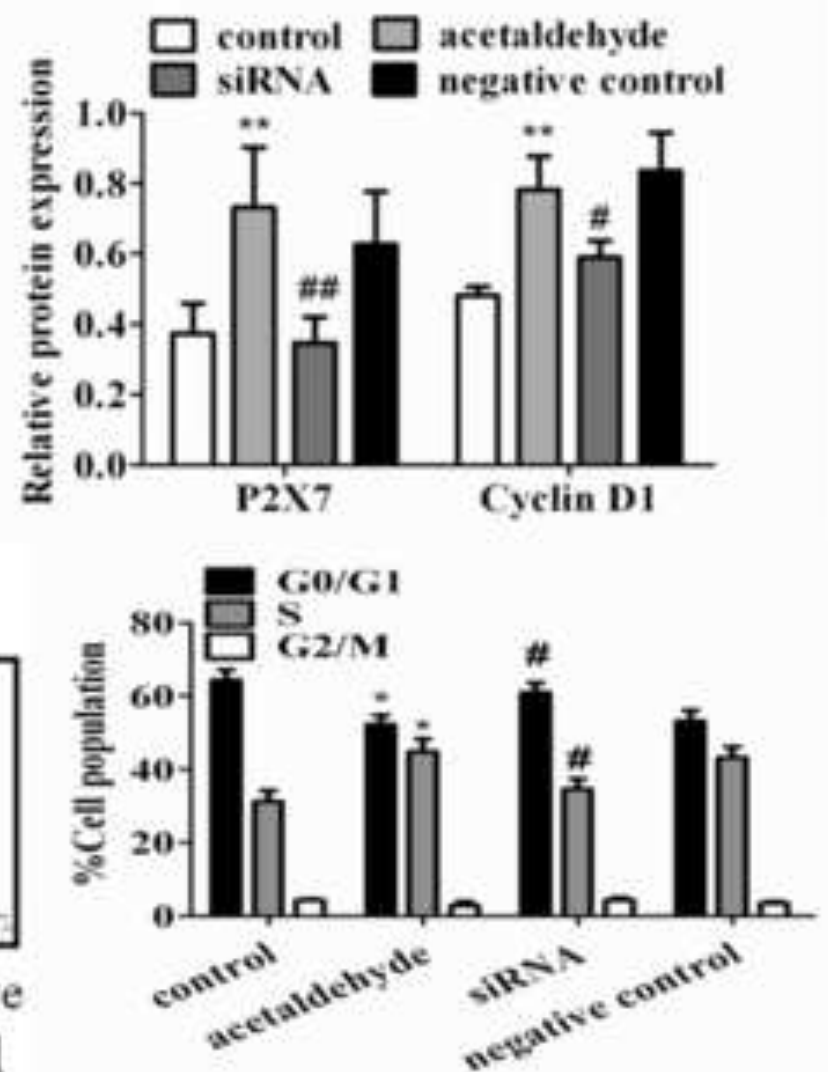
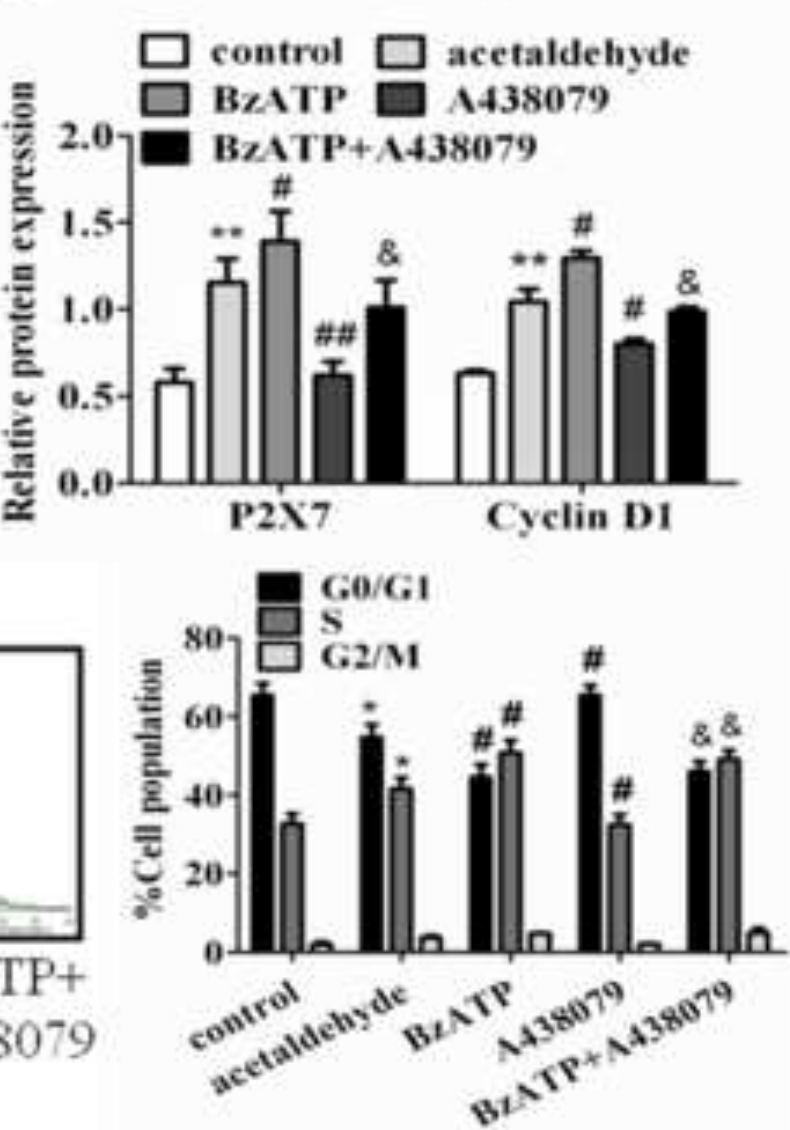


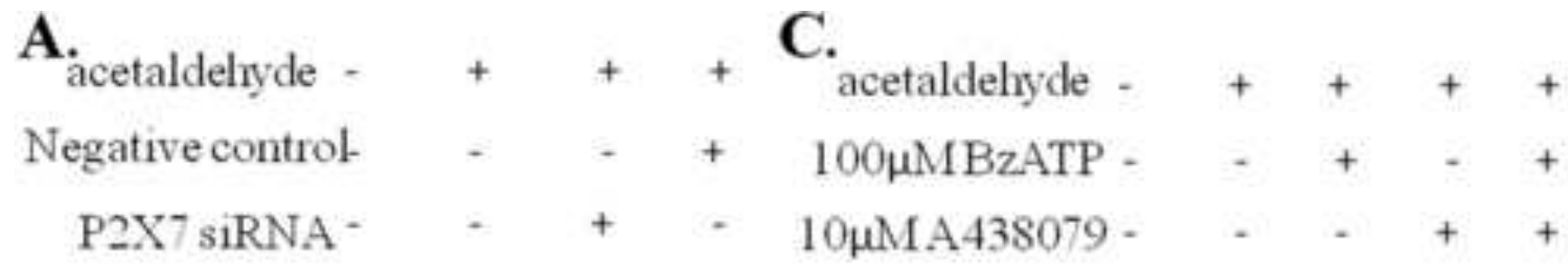
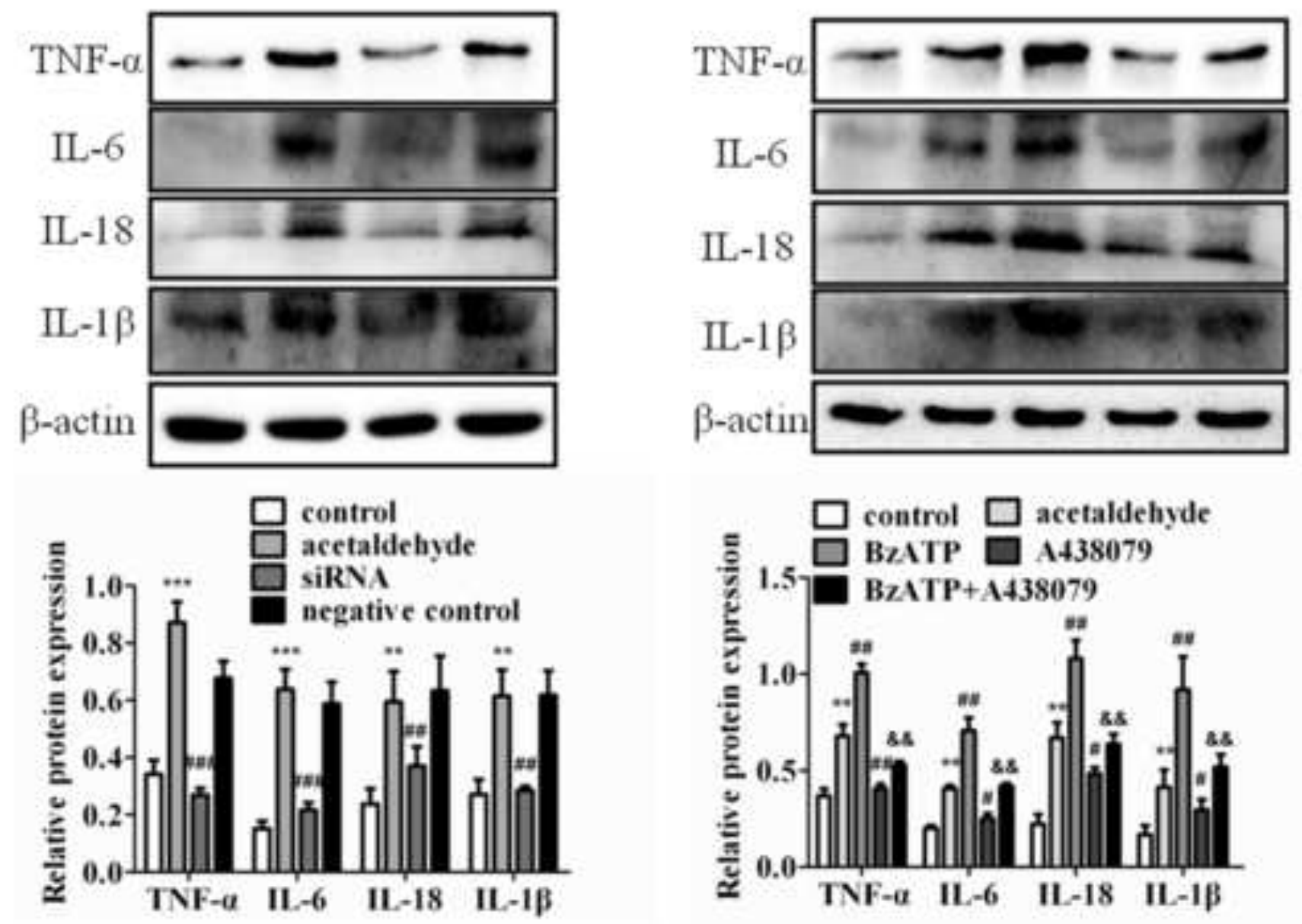

B.
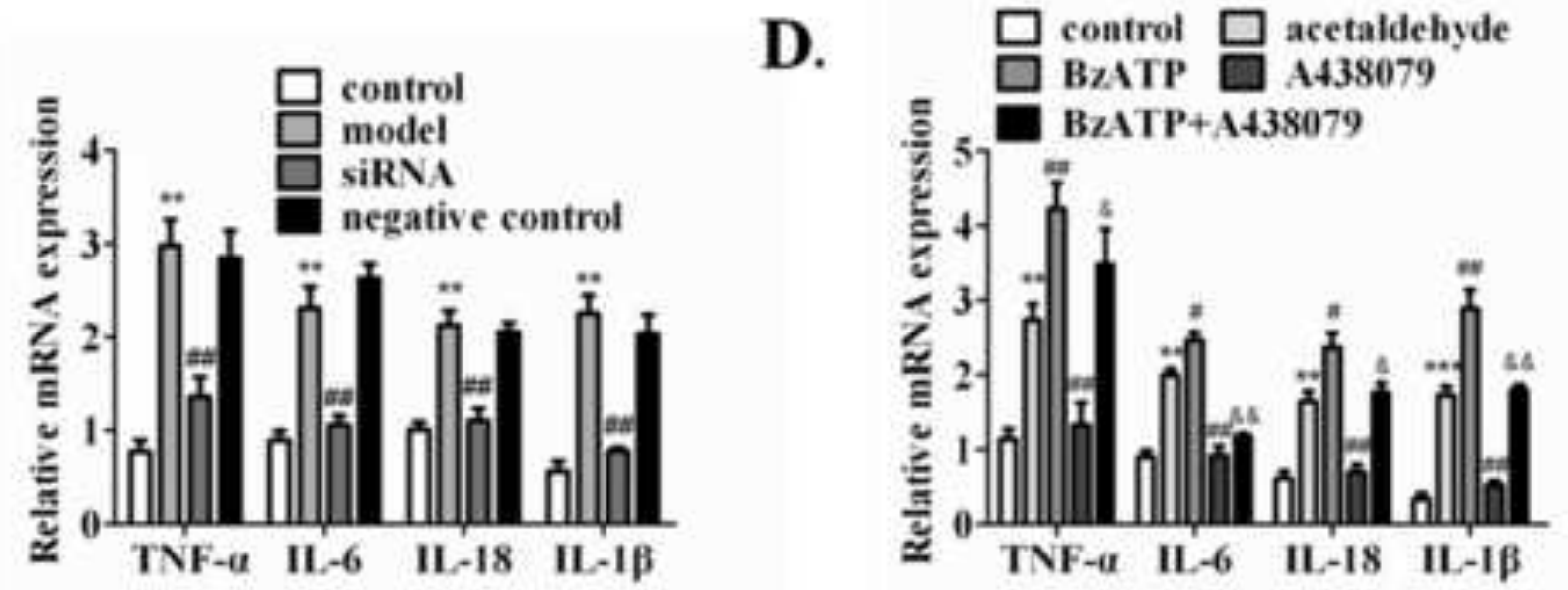
A.

acetaldehyde -+++

Negative control - - + P2X7 SiRNA - . + +
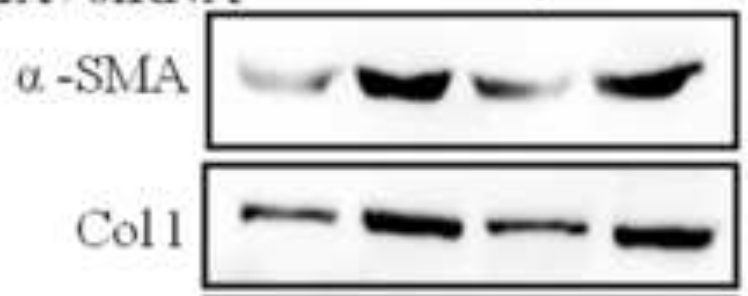

$\beta$-actin

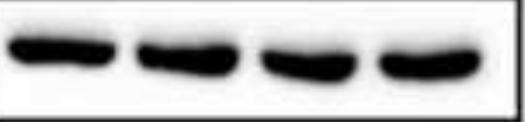

C.

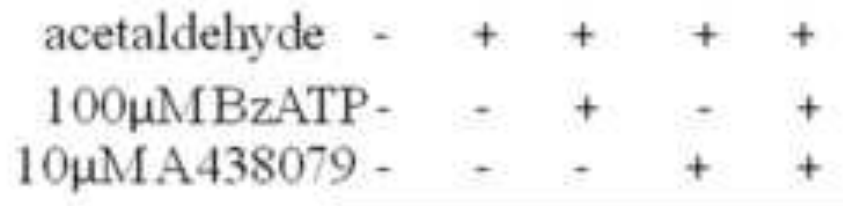

$\alpha$-SMA
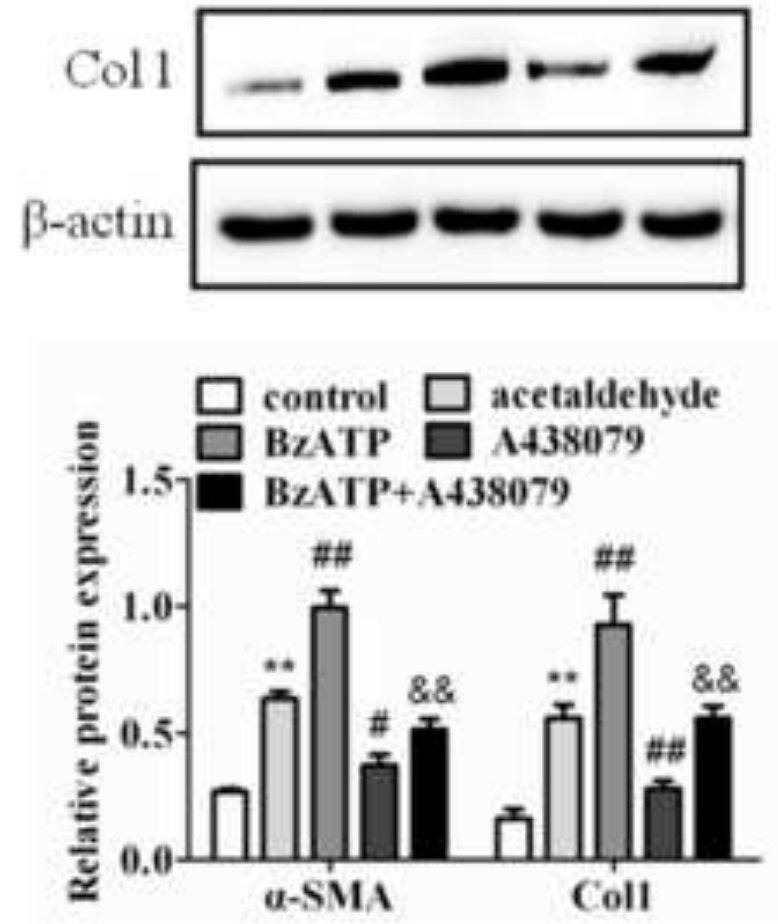

D.

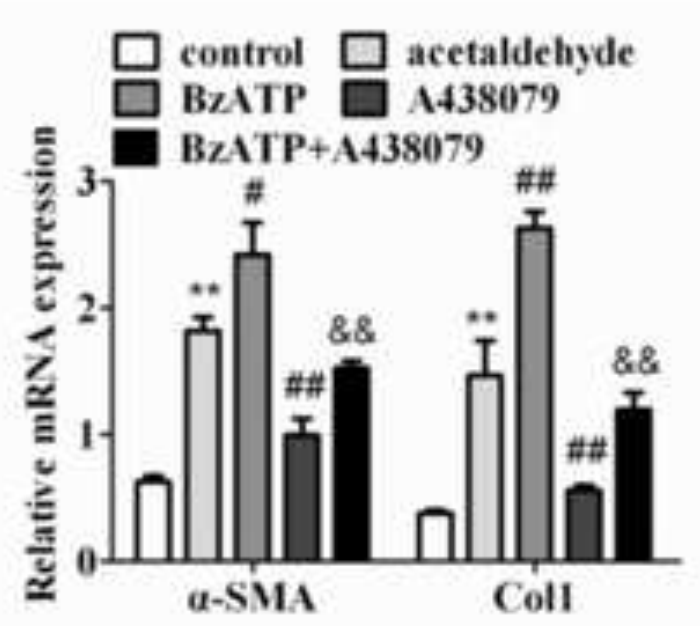

B.

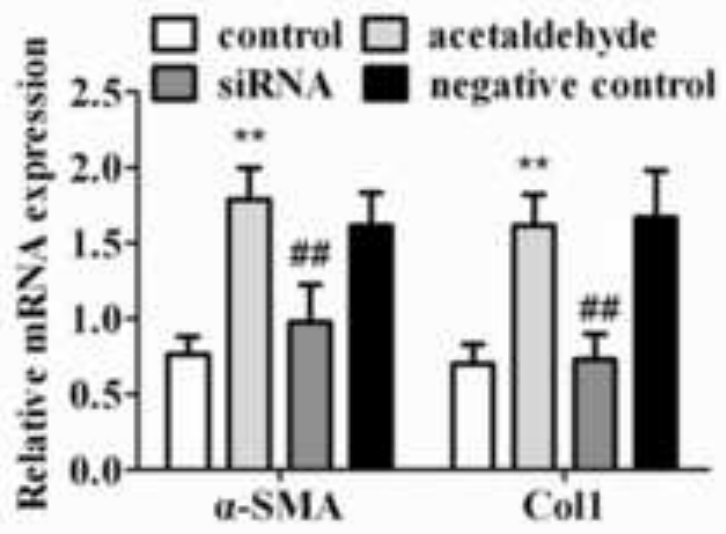




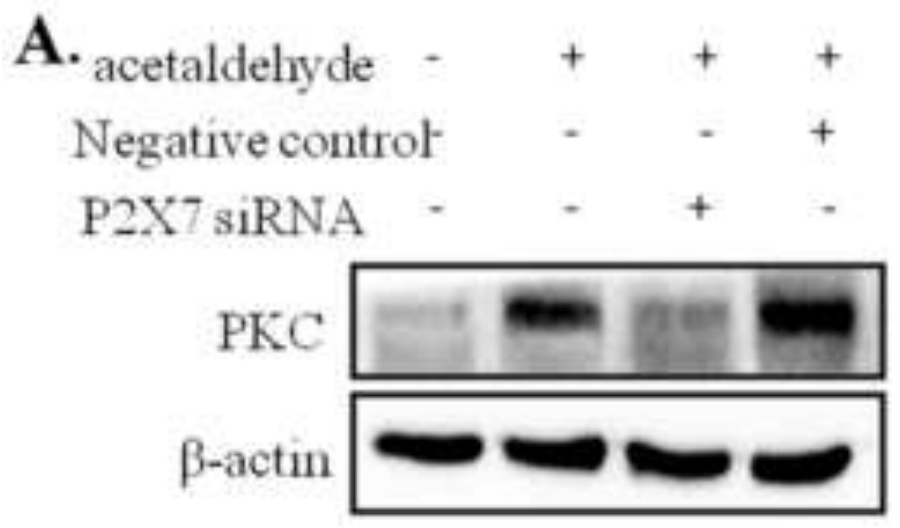
C. acetaldehyde - ++++ $100 \mu \mathrm{MBzATP}$ - - + - +

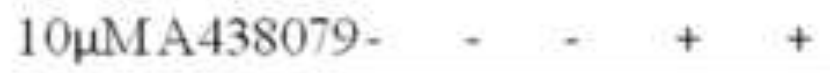
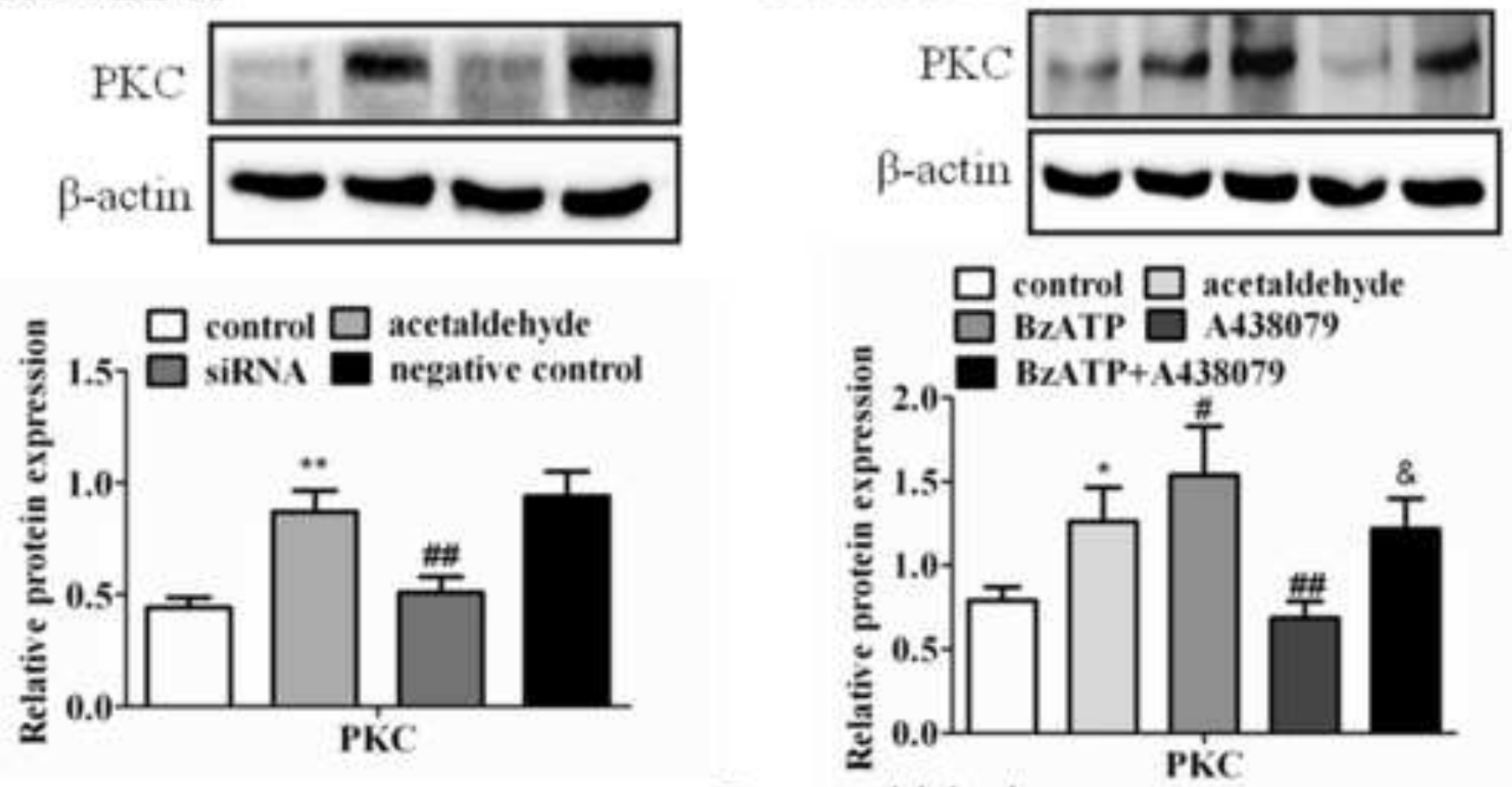

B. acetaldehyde -+++ D. acetaldehyde -+++ Negative control - - + + $\mathrm{P} 2 \mathrm{X} 7$ siRNA - + + +
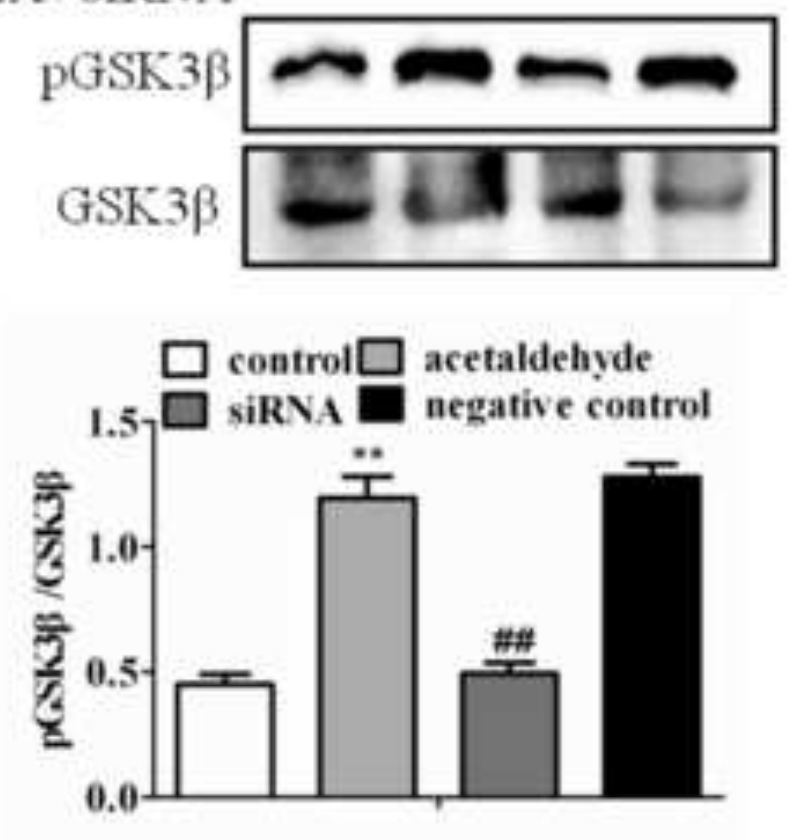
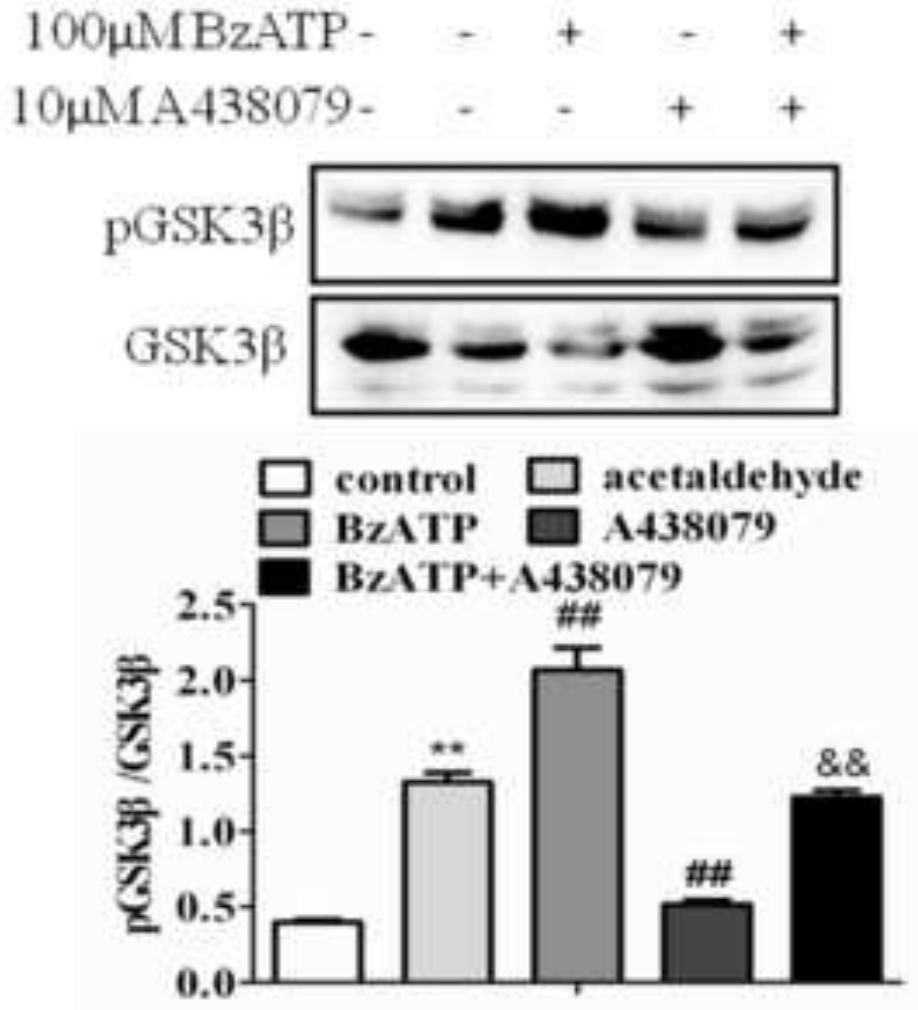


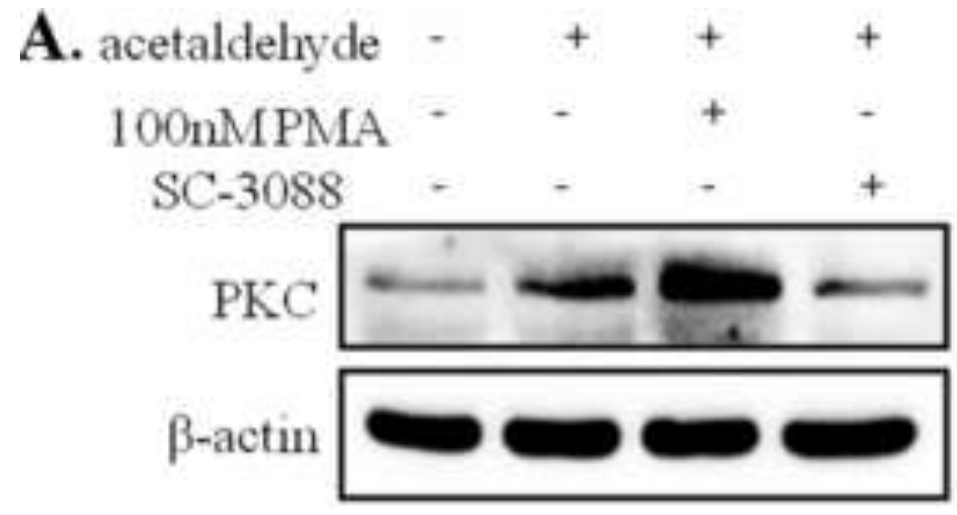

B. acetaldehyde - +++ 100nMPMA - - +

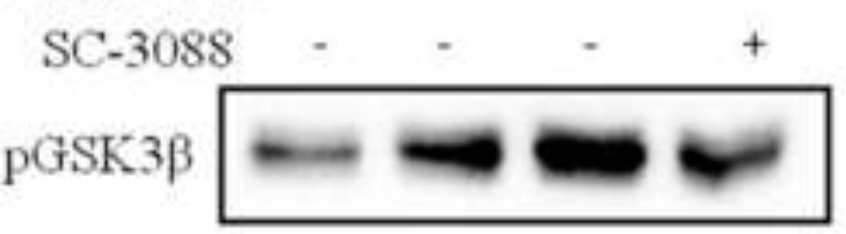

GSK $3 \beta$

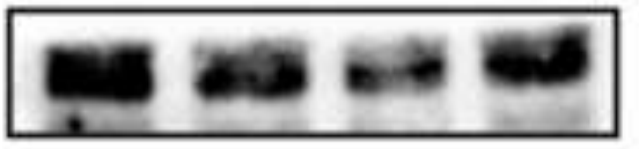

C. acetaldehyde - $++\quad+$

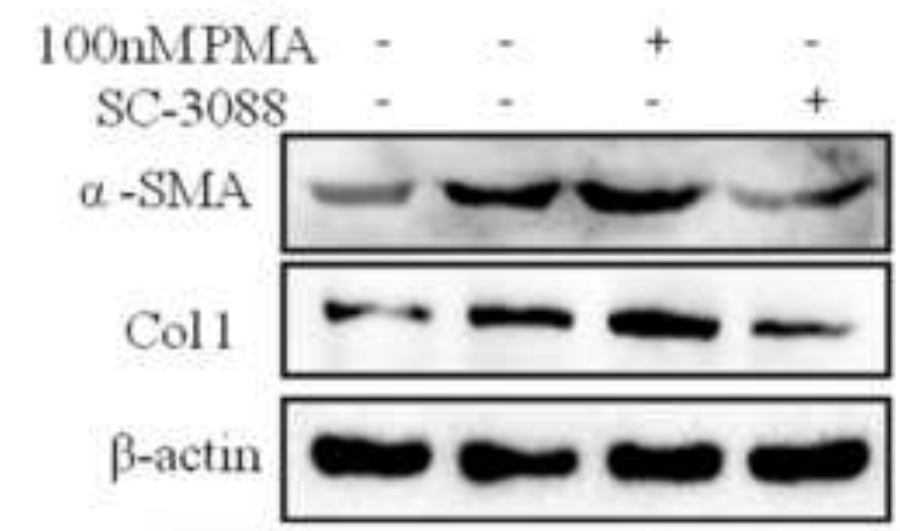

D.

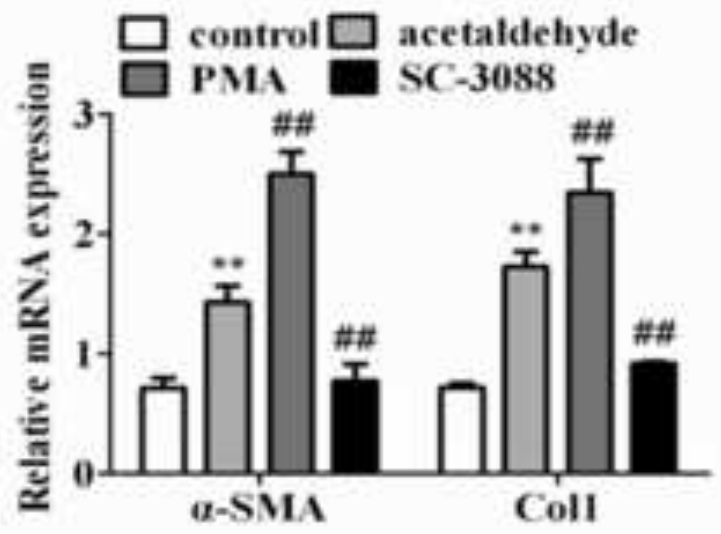

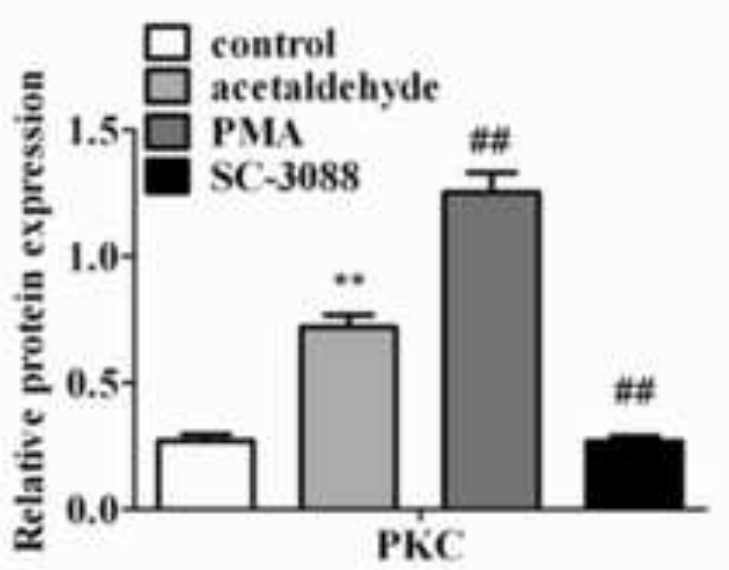
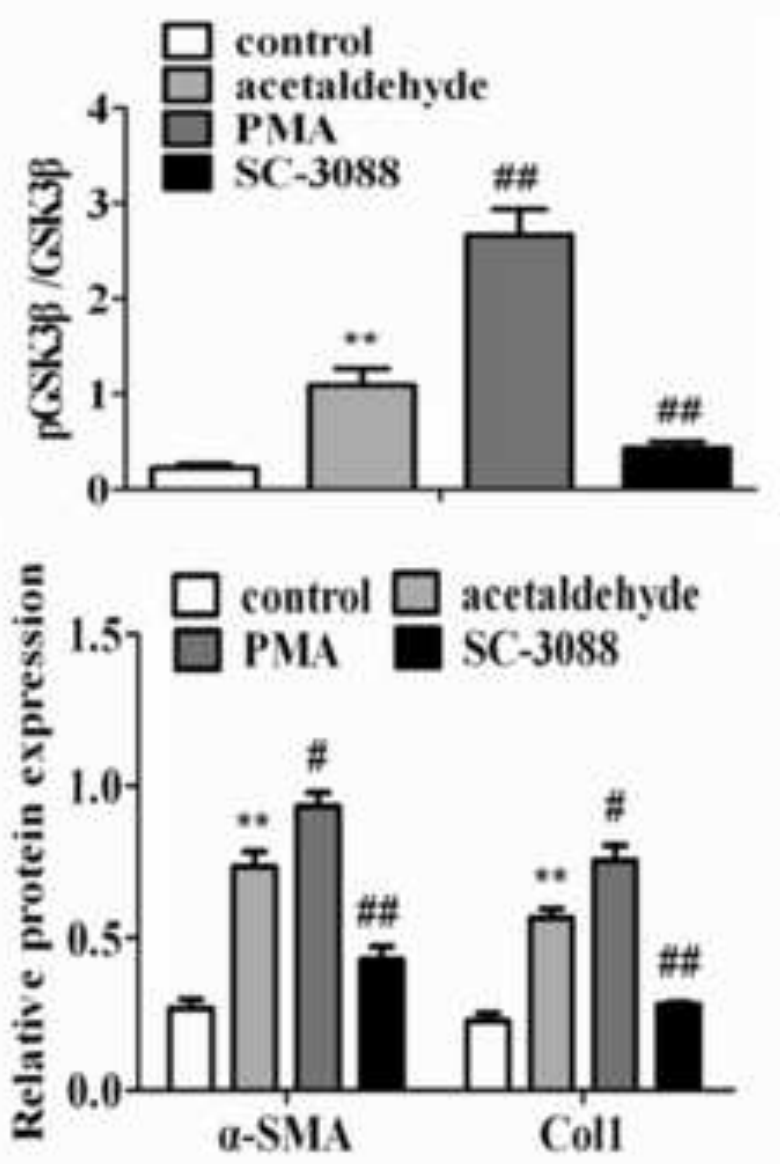
A.
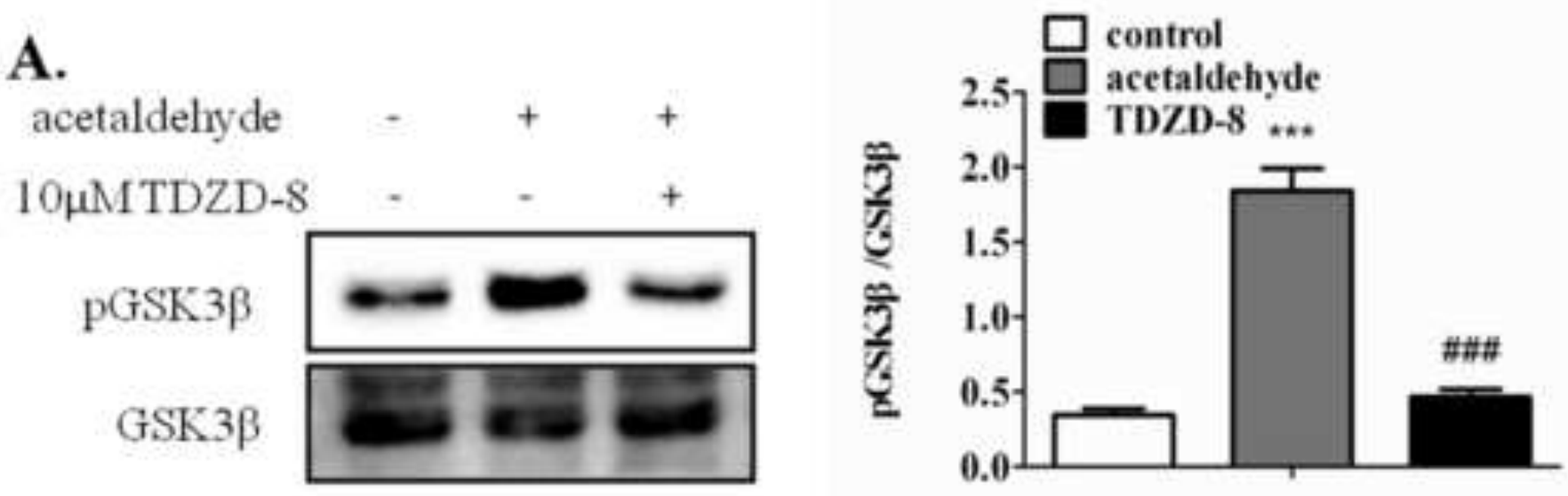

B.

acetaldehyde - ++

10 $\mathrm{MMTDZD}-8$ - +
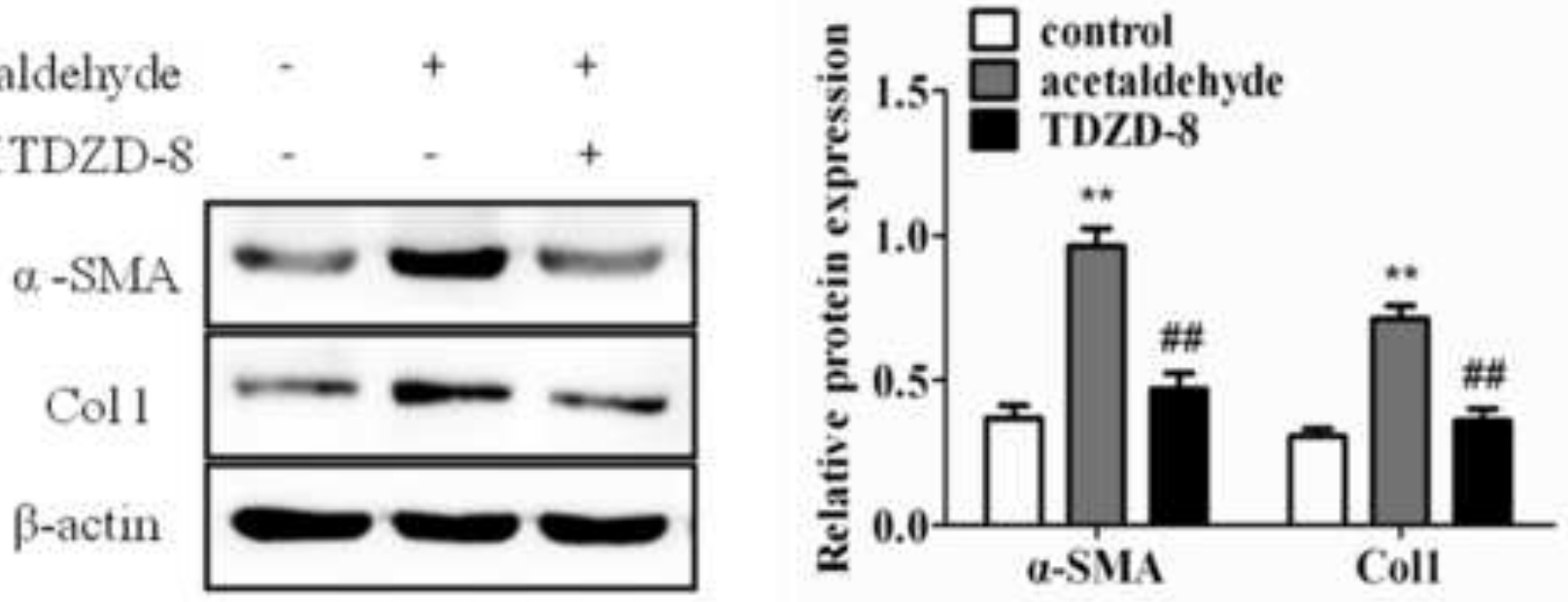

C.

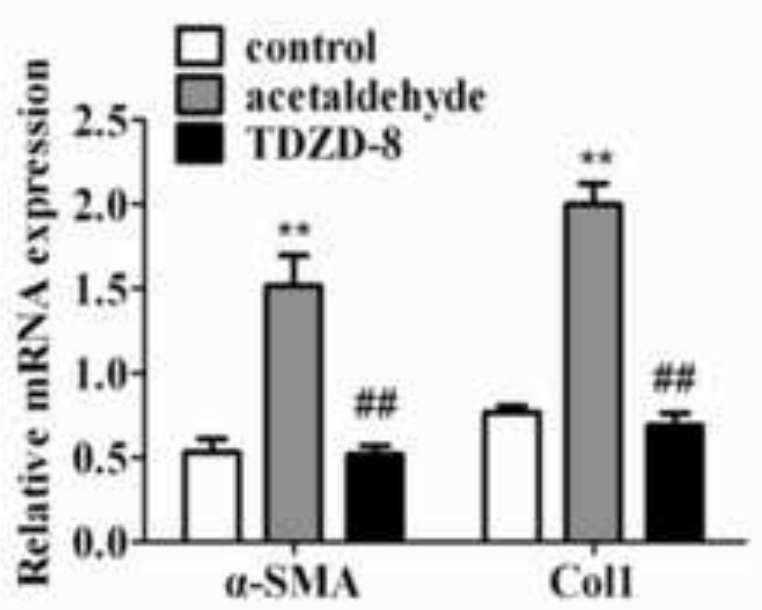


